\title{
Microstructural and texture evolution of Jethete M152 flanged-test pieces during cold rotary forging
}

\author{
Marcos Pérez \\ Advanced Forming Research Centre, University of Strathclyde, 85 Inchinnan Drive, \\ Inchinnan, Renfrew PA4 9LJ (UK) \\ *Corresponding author: Tel: +44 (0) 1415345524 \\ E-mail address: marcos.perez@strath.ac.uk
}

\section{ABSTRACT}

Rotary forging is an attractive incremental metal forming with many advantages over any other processes, requiring smaller deformation force and providing high accuracy (near-net-process). The main applications of rotary forging process include families of bevel and helical gears, and flanged components for transmissions such as disk, rollers, wheels, etc. The main aim of this work is to study the impact of rotary forging process on the microstructural and texture evolution of high-strength materials, and martensitic stainless steels in particular, during cold rotary forging process. Jethete M152 alloy is a cold formable $13 \%-\mathrm{Cr}$ martensitic stainless steel used in the aerospace industry. Jethete M152 flanged test-pieces were rotary forged at room temperature. The process was interrupted at 4 intermediate steps, providing flange reductions of $25,30,50,65$ and $70 \%$. A complex grain flow and inhomogeneous deformation patterns are developed during rotary forging, characterized mainly by the formation of a strong deformation band which run parallel to the bottom die. A transition from asymmetrical bulging (inverted mushroom) to symmetrical bulging was observed as a result of the initial lower contact area of the preform with the bottom die. From microstructural analysis by EBSD, the lath structure of Jethete M152 is gradually reoriented and changes it shape in a direction parallel to the compression plane, developing a lamellar/pancake structure in those positions with maximum deformation. These microstructural changes are accompanied with the development of a strong texture formed by a duplex $<100>+<111>$ fibers aligned with the compression axis, being the $<111>$ fiber the stronger one. These findings are in good agreement with uniaxial compression for bcc metals. The analysis of the Orientation Distribution Figures (ODF) reveals that 4 main texture components are formed in the course of the rotary forging process: Brass $\{110\}\langle 112\rangle, L\{110\}\langle 110\rangle, I\{112\}\langle 110\rangle$, and Cube $\{001\}\langle 100\rangle$. In contrast with reported literature for bcc metals, no texture component associated to the $\gamma$-fiber (\{111\} || ND) was found. 


\section{KEYWORDS}

Rotary forging, near-net-shape, texture evolution, martensitic stainless steels, cold forming.

\section{INTRODUCTION}

Rotary forging is an incremental metal forming process where two dies share a common central axis and the upper tool, usually with a conical geometry, is inclined at a certain angle,. The inclined upper tool results in a partial contact area onto the upper surface of the workpiece. The contact area moves circumferentially with the rotating die causing plastic deformation to spread incrementally throughout the workpiece. This technology is representative of processes with local deformation (Hua et al., 2009a). Rotary forging has many advantages over any other processes: smaller deformation force, longer die life, less investment in equipment (Nowak et al., 2008), it does not require heating, provides high accuracy and good quality of the formed surface (Deng et al., 2011).

Rotary forging has been analyzed extensively from the mechanical point of view. Standring et al. (1980) studied the plastic deformation introduced during the indentation phase. The same author analyzed the importance of the nutation angle in rotary forging (Standring, 1999) and the characteristic features of this process (Standring, 2001). A general description of this technology is also provided by Plancak et al. (2012). Other papers have analyzed the rotary forging process by means of simulation and numerical analysis. Liu et al. (2001) reported a numerical analysis of the flange formation in a cylinder as a workpiece. Hua et al. (2009b) investigated the effect of the cylindrical workpiece on rotary forging process. The same authors (Hua et al., 2009c) studied the plastic deformation behavior under different contact patterns.

Despite the large amount of research work done so far, due to the periodical local loading and continuous shifting of the contact area, the deformation mechanism is reported to be very complex and has not been fully understood (Hua et al., 2009a). Concerning the microstructural and texture evolution during rotary forging, Mangas et al. $(2012,2013)$ reports microstructural analysis of rotary forged Inconel 718 at high temperature, trying to relate indirectly the amount of deformation with the final grain size. However, this type of information provides little insight about the deformation mechanisms of rotary forging process, especially at room temperature. More recently, Han et al. (2016) studied the microstructural and texture evolution during cold rotary forging of spur bevel gears made of a ferritic-pearlite steel. As will be discussed, the resulting texture in this latter paper presents similarities but also important differences with the main findings of the present work. 
In the present work, the cold rotary forging process imparts a remarkable deformation on the flanged-test pieces with thickness reduction up to $70 \%(\varepsilon=1.4)$. Such levels of deformation result into a sharp texture, especially in regions with localized deformation. In this sense, the microstructural and texture evolution of bcc metals during severe plastic deformation processes such as equal-channel angular extrusion (ECAE) has been investigated extensively. Li et al. (2005a) studied by modelling the texture formation during ECAE for bcc metals. The same authors (Li et al., 2005b) also analyzed the texture formation for both bcc and fcc metals in direct comparison with simple shear. Li et al. (2006) reported the effect of ECAE processing route on the texture development for an interstitial-free (IF) steel. In a similar fashion, Bhowmik et al. (2009) also analyzed the microstructural and texture evolution of an IF steel processed by ECAP. Beyerlein et al. (2009) examined the state of the art in texture development in the field of severe plastic deformation for bcc, fcc and hcp metals.

Concerning torsion, Baczynski et al. (1996) studied the texture development during torsion for high purity $\alpha$-iron and two IF steels. These papers provide a good insight about ideal texture components in shear as the main deformation mode. However, other deformation processes such as drawing, rolling, plain strain compression have no relationship with ECAE, and the deformation is completely different, leading to different textures (Beyerlein et al., 2009). The microstructural and texture evolution during cold rolling of bcc metals is also analyzed in a significant number of papers. Holscher et al. (1991) studied the rolling and recrystallization texture of bcc steels. Raabe et al. (1993) analyzed the texture formation of ferritic stainless steels. Holscher et al (1994) investigated the relationship between rolling and shear texture in both bcc and fcc metals. Inagaki et al. $(1972,1994)$ reviewed the development of rolling textures in low-carbon steels. Hutchinson et al. (1999) performed a study about the evolution of textures and substructures during cold rolling, up to 95\% reduction, of a low-carbon steel. More recently, Yan et al. (2009) studied the texture evolution of an $11 \% \mathrm{Cr}$ ferritic stainless subjected to $80 \%$ thickness reduction by cold rolling. Herrera et al. (2009) studied the texture and mechanical properties evolution of a medium carbon steel during $80 \%$ of reduction by cold rolling. Parida et al. (2010) analyzed the texture developed after a thickness reduction of $88 \%$ in a $9 \mathrm{Cr}$-1Mo ferritic steel. Sidor et al. (2012) studied the texture evolution of cold rolled electrical steels and its impact on the magnetic properties.

Despite the amount of published work describing the texture developed in bcc metals during manufacturing/deformation processes such as ECAP, rolling, torsion, etc., no relevant information was found about the microstructural and texture evolution of martensitic steels under incremental forming process, and 
rotary forging in particular. It is clear that additional work is required to fully understand a near-net-shape process as complex as rotary forging. The objective of the present work is to investigate the impact of rotary forging on the microstructural and texture evolution of aerospace materials such as Jethete M152 (13\% Cr martensitic stainless steel). Another main purpose is to analyse the influence of incremental forming processes on the strain distribution and mechanisms of deformation involved for high-strength materials.

\section{MATERIALS AND METHODOLOGY}

Jethete M152 bars (MSRR6503) with $60 \mathrm{~mm}$ in diameter was supplied in as-tempered condition with a hardness of $339 \mathrm{HV} 2$. The chemical composition is given in Table 1. From the $60 \mathrm{~mm}$ diameter bars, flanged test-pieces with $49.60 \mathrm{~mm}$ external diameter and $12.5 \mathrm{~mm}$ of flange thickness were machined along the rolling direction $(R D)$. In a previous work, the impact of annealing treatments on the softening and work hardening behaviour of Jethete M152 alloy for subsequent cold forming processes was studied (Pérez, 2017b). The main findings of the work showed that only subcritical annealing treatments $\left(T<A_{c 1}\right)$ provide a significant softening to Jethete M152 alloy. However, no significant differences in terms of ductility parameters and work hardening behaviour were found in direct comparison to as-tempered condition. For this reason, the flanged-test pieces were processed in as-received condition (as-tempered), no applying any heat treatment prior to (cold) rotary forging.

Table 1. Jethete M152 chemical composition

\begin{tabular}{cccccccccc}
\hline $\mathrm{C}$ & $\mathrm{Si}$ & $\mathrm{Mn}$ & $\mathrm{S}$ & $\mathrm{P}$ & $\mathrm{Ni}$ & $\mathrm{Cr}$ & $\mathrm{Mo}$ & $\mathrm{V}$ & $\mathrm{Fe}$ \\
0.11 & 0.22 & 0.68 & 0.0008 & 0.016 & 2.67 & 11.41 & 1.56 & 0.28 & Compl. \\
\hline
\end{tabular}

Rotary forging trials were conducted at the National Metalforming Centre (NMC, Nottingham) on a spin and precession rotary forge equipment with an angle of inclination ( $\theta$ ) fixed at $1^{\circ}$, by applying a maximum load of 200 t. The flanged-test preform was placed in the bottom die, not being necessary to fix it. Figure 1 shows a schematic representation of this rotary forging process. The upper die is a conical die which oscillates around the vertical machine, providing the rotary motion. Simultaneously, the lower die pushes the preform against the upper tool, resulting into axial compression. During this rotary forging process, the preforms were shaped in the space that is formed between the upper and lower dies. Based on the geometry of the preform and the tool design, the deformation is mainly localized in the flange as shown in Figure 2, where the axial/transverse sections of both the preform (flanged-test piece) and the rotary forged part with the maximum reduction (70\%) can be observed. The selected geometry replicates one the most common applications of the rotary forging process, but at small scale, 
which is the flange formation from a cylindrical workpiece The main purpose of the conical shape beneath the flange (basement) is to stabilize the workpiece during the rotary forging process.

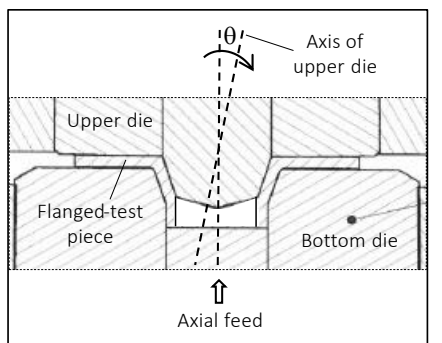

Figure 1. Schematic representation of rotary forging of flanged test-pieces.

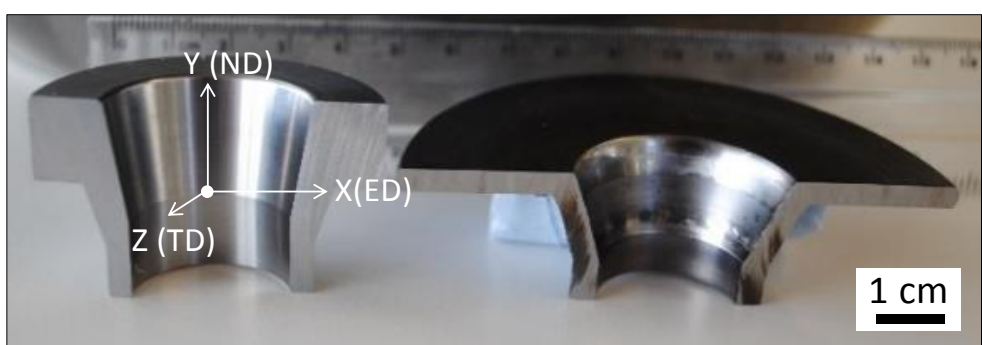

Figure 2. Comparison between the initial preform (left side) and a rotary forged test piece with a $70 \%$ of reduction (right side).

In order to analyze the rotary forging process at different stages, the forging trials were stopped at 4 intermediate steps. With a starting flange thickness of $12.5 \mathrm{~mm}$ (preform), Figure 3 shows the sequence of 5 rotary forged flanged test-pieces with increasing thickness reduction $(25,30,50,65$ and $70 \%)$ analyzed in the present work. The $70 \%$ in thickness reduction corresponds to the maximum deformation, making use of the total load capacity of the rotary forging equipment (20 ton). Table 2 shows how the decrease of flange thickness ( $t$ ) is accompanied by a lateral expansion, and therefore an increase in the external diameter $\left(D_{\text {ext }}\right)$, with increasing amounts of deformation (\%).

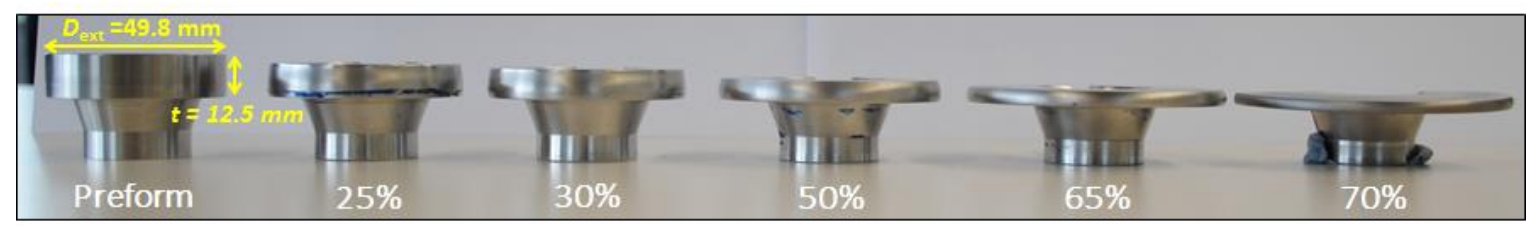

Figure 3. Sequence of rotary forged flanged-test pieces with increasing thickness reduction

Table 2. Geometry evolution of rotary forged flanged-test pieces

\begin{tabular}{ccccccc}
\hline \multirow{2}{*}{ Geometry } & \multicolumn{5}{c}{ Thickness reduction of the flange (\%) } \\
& Preform & $25 \%$ & $30 \%$ & $50 \%$ & $65 \%$ & $70 \%$ \\
\hline Flange thickness, $t(\mathrm{~mm})$ & 12.5 & 9.5 & 8.6 & 6.1 & 4.4 & 3.8 \\
\hline Ext. Diameter, $D_{\text {ext }}(\mathrm{mm})$ & 49.6 & 55.6 & 58.1 & 66.4 & 76.8 & 82.6 \\
\hline
\end{tabular}

Rotary forged test pieces were sectioned transversally (parallel to the compression axis) for microstructural and texture characterization. Villella's etching was used to reveal the microstructure of Jethete M152 alloy. Grain flow analysis coupled with hardness maps were conducted on the flange of rotary forged flanged-test pieces. Grain flow maps were obtained by using ALICONA microscopy, where micrographs taken at magnification of $5 x$ were collected and combined automatically. Micro-hardness measurements (Vickers) were obtained by using Zwick ZHV1 - micro Vickers hardness tester with a load of $2 \mathrm{~kg}$ (HV2). A distance of $0.5 \mathrm{~mm}$ among consecutive 
indentations was considered. Hardness maps were generated in order to evaluate the strain distribution of rotary forged parts.

The microstructural and texture evolution of rotary forged flanged-test pieces was investigated by using the electron backscattering diffraction technique (EBSD). A field emission gun-scanning electron microscope (Oxford Quanta 250) operating at an accelerating voltage of 20kV and equipped with EBSD detector was used. The surface of flanged test-pieces was prepared by conventional polishing techniques with diamond suspension down to 1 $\mu \mathrm{m}$ and finally polishing in a vibratory machine by using a colloidal silica suspension with a particle size of 0.05 $\mu \mathrm{m}$. The reference axis for EBSD scans and subsequent analysis were shown previously in Figure 2, where $\mathrm{X}, \mathrm{Y}$ and Z axis correspond to External Direction (ED), Normal Direction (ND) and Transversal Direction (TD), respectively. The ND direction (Y-axis) is the compression axis of the rotary forging process, but also the original rolling direction $(R D)$ from the as-received material (Jethete M152 bars); $E D$ (X-axis) is the direction in which the lateral expansion of the external diameter ( $D_{\text {ext }}$ ) takes place as a result of the thickness reduction $(t)$; and the TD (Z-axis) corresponds to the direction perpendicular to the surface in which microstructural analysis was conducted. EBSD measurements were carried out in the plane perpendicular to the sample transverse direction (ED-ND plane), being the EBSD samples tilted $70^{\circ}$ with respect to the X-axis (ED). A step size of $0.2 \mu \mathrm{m}$ was used.

Inverse pole figures (IPF) coupled with Image Quality (IQ) maps were obtained from the analysis of scanned data by using Tango software from CHANNEL 5. The results of the texture measurements are presented in the form of pole figures $(\{100\},\{110\},\{111\})$ and orientation distribution function (ODF) in the $\varphi_{2}=0^{\circ}$ and $45^{\circ}$ (const. sections). The orientation data was processed with Mambo and Salsa software, for pole figures and ODF, respectively. The textures were calculated by the harmonic series expansion method assuming orthorhombic sample symmetry and by superimposing a Gaussian peak for each individual orientation with a spread of $5^{\circ}$ around the exact orientation. The pole density was calculated from each orientation expressed as the Gaussian peak with a scattering of 5 and $L_{\max }=22$ in the series expansion. During data processing, a maximum allowable angle of deviation was set at $10^{\circ}$. 


\section{RESULTS}

\subsection{Geometric analysis}

In order to analyze the geometrical tolerances of the rotary forged flanged test pieces, 3 measurements $\left(120^{\circ}\right.$ apart) for both external diameter and flange thickness was carried out, see Table 3. Maximum tolerances of 0.11 and $0.02 \mathrm{~mm}$ were found for the external diameter and flange thickness, respectively.

Table 3. Geometrical tolerances of rotary forged flanged-test pieces

\begin{tabular}{|c|c|c|c|c|c|c|c|c|c|c|}
\hline \multirow{2}{*}{$\begin{array}{c}\text { Thickness } \\
\text { reduction (\%) }\end{array}$} & \multicolumn{5}{|c|}{ External diameter $(\mathrm{mm})$} & \multicolumn{5}{|c|}{ Flange thickness (mm) } \\
\hline & $d_{1}$ & $d_{2}$ & $d_{3}$ & Mean & $\begin{array}{l}\text { Std. } \\
\text { Dev. }\end{array}$ & $t_{1}$ & $t_{2}$ & $t_{3}$ & Mean & $\begin{array}{l}\text { Std. } \\
\text { Dev. }\end{array}$ \\
\hline $25 \%$ & 55.82 & 55.71 & 55.65 & 55.73 & 0.07 & 9.52 & 9.54 & 9.51 & 9.52 & 0.01 \\
\hline $30 \%$ & 58.05 & 58.02 & 58.09 & 58.05 & 0.03 & 8.59 & 8.61 & 8.56 & 8.59 & 0.02 \\
\hline $50 \%$ & 66.34 & 66.43 & 66.41 & 66.39 & 0.04 & 6.15 & 6.14 & 6.15 & 6.15 & 0.00 \\
\hline $65 \%$ & 76.71 & 76.9 & 76.73 & 76.78 & 0.09 & 4.44 & 4.40 & 4.43 & 4.42 & 0.02 \\
\hline $70 \%$ & 82.55 & 82.43 & 82.69 & 82.56 & 0.11 & 3.75 & 3.77 & 3.75 & 3.76 & 0.01 \\
\hline
\end{tabular}

Figure 4 shows the GOM scans (ATOS) of the rotary forged flanged test piece with $70 \%$ of thickness reduction, plotting the deviation to a best fit plane for both top and bottom surfaces. These results clearly reveal the tight flatness tolerances achieved on the flange $( \pm 0.05 \mathrm{~mm})$ of the flanged test piece during the rotary forging process.

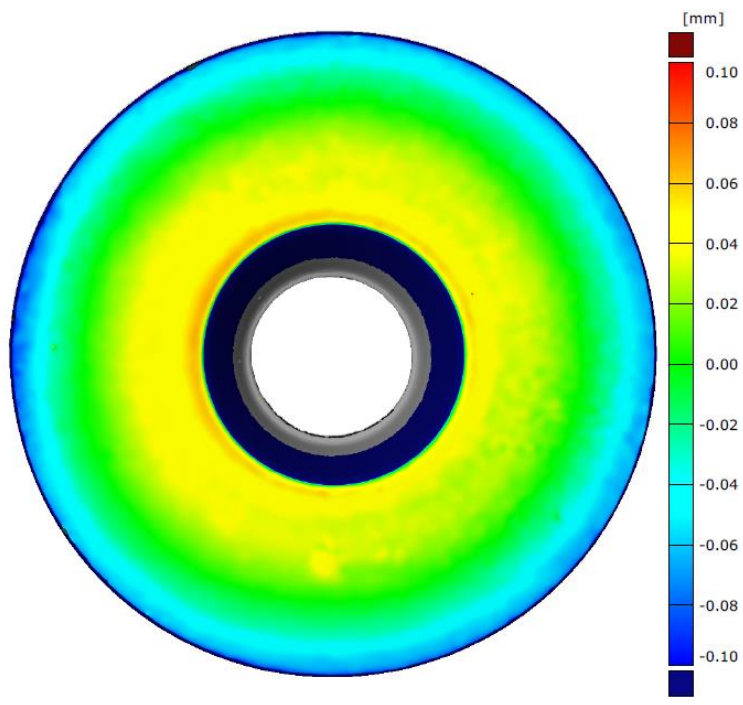

a) Top surface

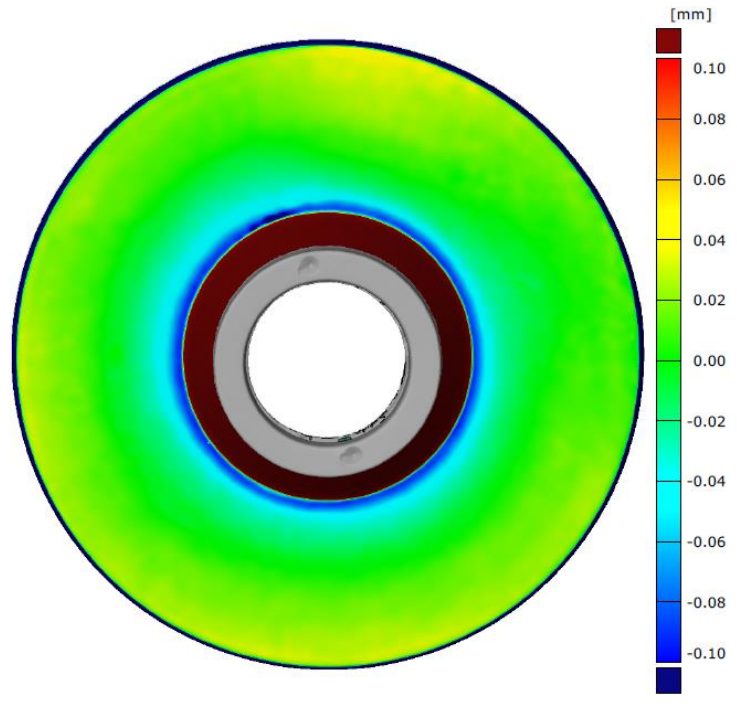

b) Bottom Surface

Figure 4. GOM scans of top a) and bottom b) surface of the rotary forged flanged test piece with $70 \%$ of thickness reduction. 


\subsection{Flow analysis and hardness distribution}

In the present work, analysis of both grain flow and hardness distribution were conducted on axial/transverse sections of flanged-test pieces, and on the flange in particular, where the deformation is mainly localized. Figure 5 shows the evolution of the grain flow patterns with increasing amount of deformation along with the hardness maps (HV2) which provides a fair estimation of the strain distribution across the rotary forged test pieces. The hardness maps and grain flow maps are overlapped in order to make easier the identification of regions with localized deformation. From these figures (Figure 5), it is obvious the complex grain flow and inhomogeneous deformation pattern developed in the course of the rotary forging process (see Figure 5.e).

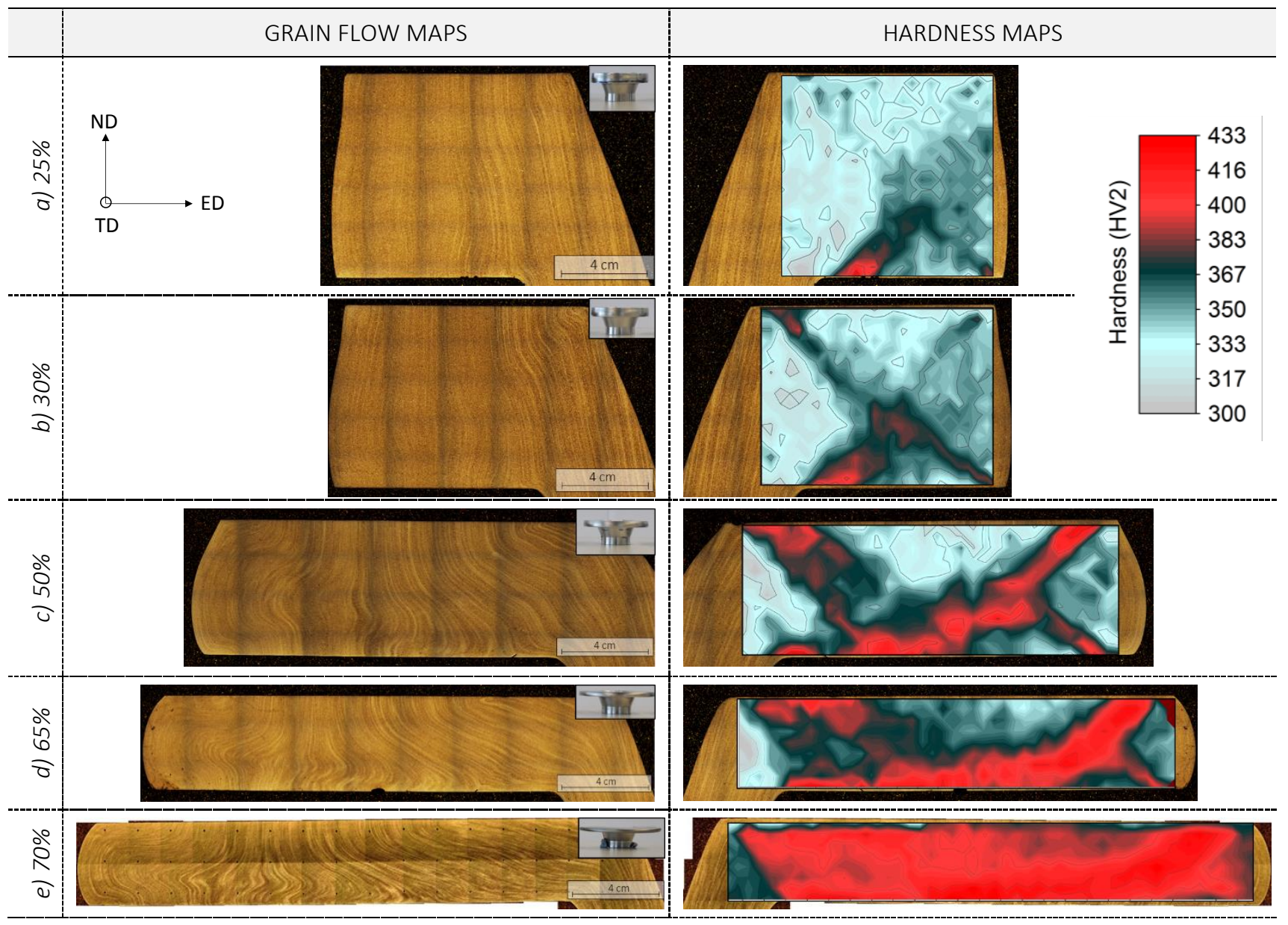

Figure 5. Evolution of grain flow pattern and hardness distribution of flanged-test pieces in the course of rotary forging process.

At early stages of deformation, for a $25 \%$ reduction (see Figure 5.a, hardness map), the plastic deformation is mainly localized close to the bottom die with the formation of an inverted " $\mathrm{V}$ " shape. With subsequent deformation (Figure 5.b, 30\% reduction, hardness map), the inverted "V" shape growths to the characteristic " $\mathrm{X}$ " shape commonly observed in upsetting processes along with the formation of the dead zones close to the upper 
tool. As it can be seen in the hardness maps (Figure 5.a \& b), the center of the inverted "V" shape and the subsequent " $\mathrm{X}$ " shape for 25 and 30\% reduction, respectively, is located in those regions where the lateral expansion of microstructural bands can be observed in the corresponding grain flow maps. This latter observation can well explain the formation of the asymmetrical bulging at early stages of rotary forging process, clearly located closer to the bottom die. For a 50\% reduction (Figure 5.c, hardness map), a predominant deformation band "/" inside the " $X$ " shape is developed, running diagonally from bottom/interior to top/exterior positions. For a $65 \%$ reduction (Figure 5.d, hardness maps), it is even more evident that the plastic deformation is highly localized in this main deformation band, "I". For the $70 \%$ of reduction, Figure 5.e (hardness map), the main deformation band is highly stretched and runs almost parallel along the bottom die. In addition, the high levels of deformation start to be accommodated in those regions previously strain-free, such as the dead zone, close to the top position.

From Figure 5, the transition from an asymmetrical bulging (inverted mushroom) at the very beginning of the process (25-30\%, Figure 5.a \& b) to the final formation of a symmetrical bulging at the end of the process (70\%, Figure 5.e) can be observed. In the course of rotary forging process, apparently the center of the " $\mathrm{X}$ " shape is displaced horizontally as a result of the lateral expansion during the deformation (radial flow), stretching the main deformation band "I" as shown in Figure 6. In addition, the " $X$ " shape also describes a vertical movement across the thickness towards the bottom die. However, the relative vertical displacement of the " $X$ " center is, in fact, towards the center of the flange ( $1 / 2$ thickness). Note that vertical displacement is a small fraction of the thickness reduction which takes place at each single deformation step. Figure 7 plots the relative position of this center with the thickness by means of the ratio $(d / t)$, being $d$ the distance between the center of the " $X$ " shape and the bottom die, and $t$ the flange thickness. Initially, for $25 \%$ of deformation the center is located at about $1 / 4$ thickness from the bottom die. With subsequent deformation, such center is linearly displaced to relative higher positions, reaching finally a $1 / 2$ thickness position for $70 \%$ of reduction. Such relative vertical displacement can well explain the transition from the asymmetrical bulging (inverted mushroom) to the final formation of a symmetrical bulging at the end of the process. Another aspect to be remarked is the continuous realignment/bending of microstructural bands observed in the interior-top corner in contact with the upper die. Initially in the preform, they are orientated vertically along the original rolling direction, but they suffer a rotation close to $90^{\circ}$ in the course of rotary forging process. 


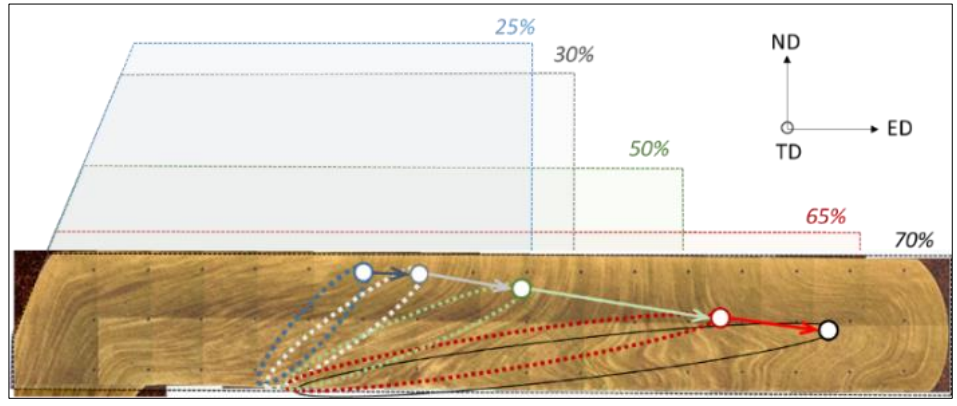

Figure 6. Lateral and vertical displacement of the center of " $X$ " shape (open circles) and evolution of the main deformation band "I" (dotted lines) in rotary forged parts with increasing thickness reductions (\%)

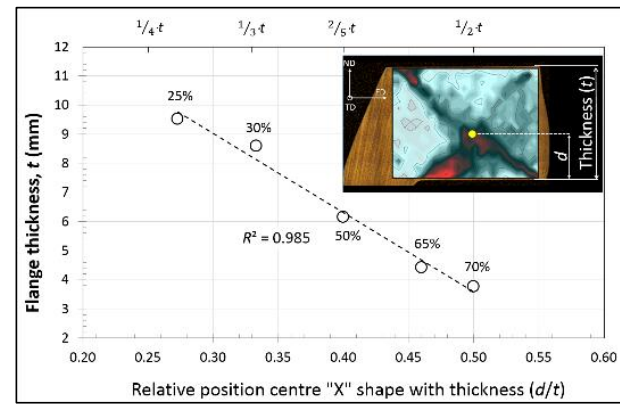

Figure 7. Evolution of the relative position of the center of " $X$ " shape with respect the bottom die $(d / t)$.

\subsection{Microstructural and texture evolution}

Electron Back-Scattered diffraction technique (EBSD) was used in order to analyze the microstructural and texture evolution of cold-worked martensite during rotary forging process. Based on the hardness results (Figure 3), EBSD scans were performed in two regions on the flange of rotary forged test pieces with significant differences in strain localization and hardness distribution:

- Upper position: Region which corresponds to the dead zone showing the minimum levels of deformation/hardness.

- Bottom position: Location of the main deformation band ("/") where the maximum increase of hardness, associated to strong strain localization, was found.

Figure 8 plots EBSD maps a combination of inverse pole figure (IPF) and band contrast (BC) at top and bottom positions of rotary forged test pieces with increasing amount of thickness reduction (\%), in a direct comparison to as-received condition (as-tempered martensite). In order to make easier a direct comparison across the rotary forging process, Figure 8 shows only a $50 \%$ of the total scan area:

- The microstructure of Jethete M152 in as-received condition (Figure 8.a \& g) corresponds to lath martensite characterized by a fine structure, commonly observed in low-carbon martensitic steels (Krauss, 1999). Lath martensite in steels has a hierarchical multi-scale substructure including packets, blocks and laths, where the laths are aligned into groups with the same orientation (packets), separated by high angle boundaries. The substructure of lath martensite consists of a network of dislocations, as a result of the shear process during martensitic transformation $(\gamma \rightarrow \alpha)$ (Krauss, 1999).

- At bottom positions (Figure 8.h,l,j \& k), several structural changes can detected as rotary process proceeds. Initially, for reductions below 50\% (25 and 30\%), the lath structure are reoriented and change their shape, 
being elongated in a direction parallel to the compression plane. For reductions above $50 \%$, the lath structure is fully aligned parallel to compression plane, developing what seems to be a lamellar or pancake structure.

- At top positions (Figure 8.b,c,d,e \& f), there is no evidence of significant deformation, in terms of reorientation of structure, up to a reduction of 50\%. Even with the maximum reduction (70\%, Figure $8 . f)$, the deformation and reorientation of microstructure is much weaker than those observed at bottom positions (Figure 8.k). These observations are in good agreement with the low hardness levels found in these positions (Figure 5).

These results clearly confirm the inhomogeneous strain distribution developed across the flange in the rotary forged flanged-test pieces and the formation of dead zones close to the upper tool.

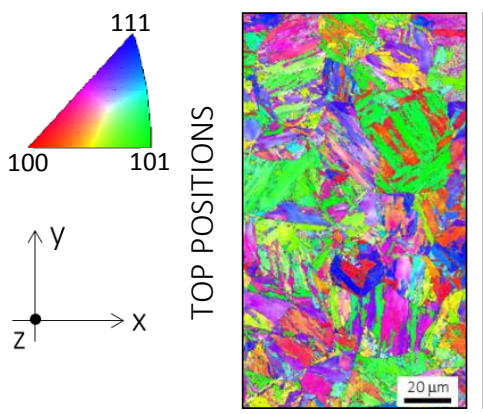

a) As-received

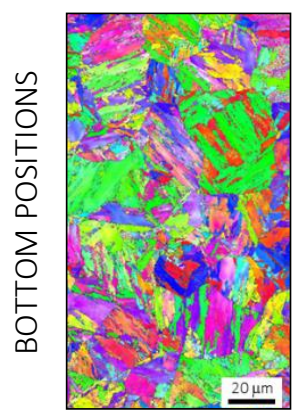

g) As-received

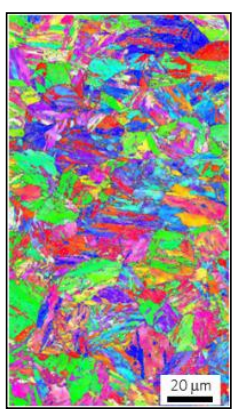

b) $25 \%$

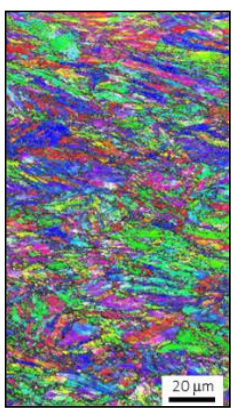

h) $25 \%$

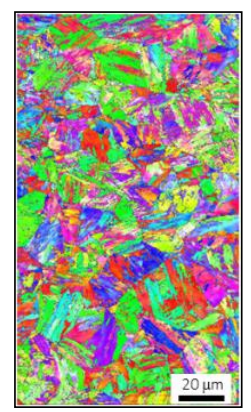

c) $30 \%$

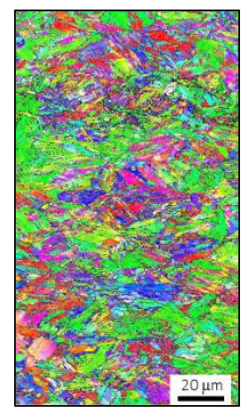

i) $30 \%$

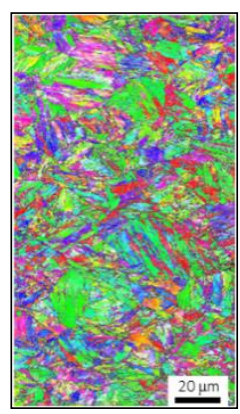

d) $50 \%$

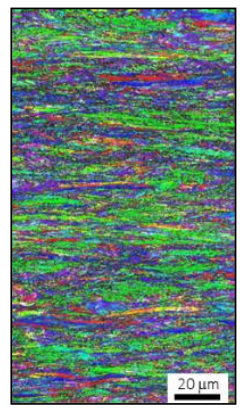

j) $50 \%$

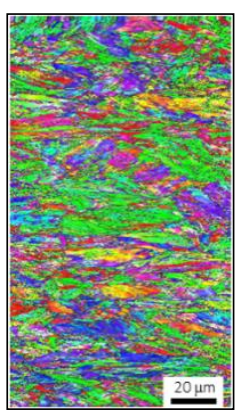

e) $65 \%$

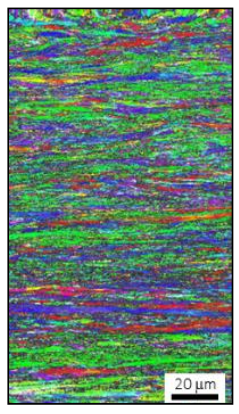

k) $65 \%$

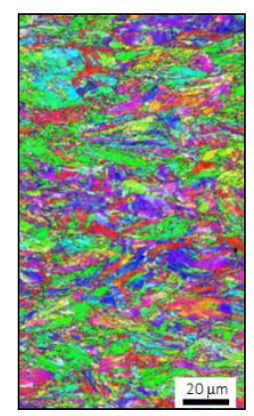

f) $70 \%$

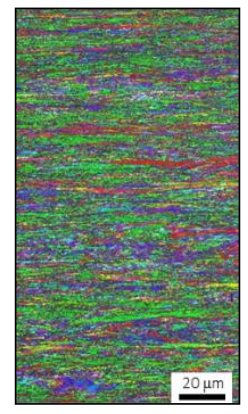

1) $70 \%$

Figure 8. Microstructural evolution of rotary forged test-pieces in as-tempered condition (a \& g) with increasing amount of thickness reduction (\%) at top $(b, c, d, e, f)$ and bottom positions $(h, l, j, k, l)$, by means of a combination inverse pole figures (IPF) + band contrast maps (BC).

In order to analyze the texture evolution during rotary forging, (100), (110) and (111) pole figures projected on the ND-plane are plotted in Figure 9. It is reported that initial texture plays an important role in the final state of the deformed structures. Small differences in initial texture and microstructure can produce large differences on final texture under the same deformation process (Li et al. 2005b). In the present work, the initial texture of preforms (Figure 9.a g) correspond to Jethete M152 in as-received condition (tempered martensite), presenting 
a very weak texture due to, presumably, texture randomization through a $\gamma \rightarrow \alpha^{\prime}$ phase transformation during both

the thermomechanical processing (Engler et al., 2009) and subsequent solution annealing treatment.
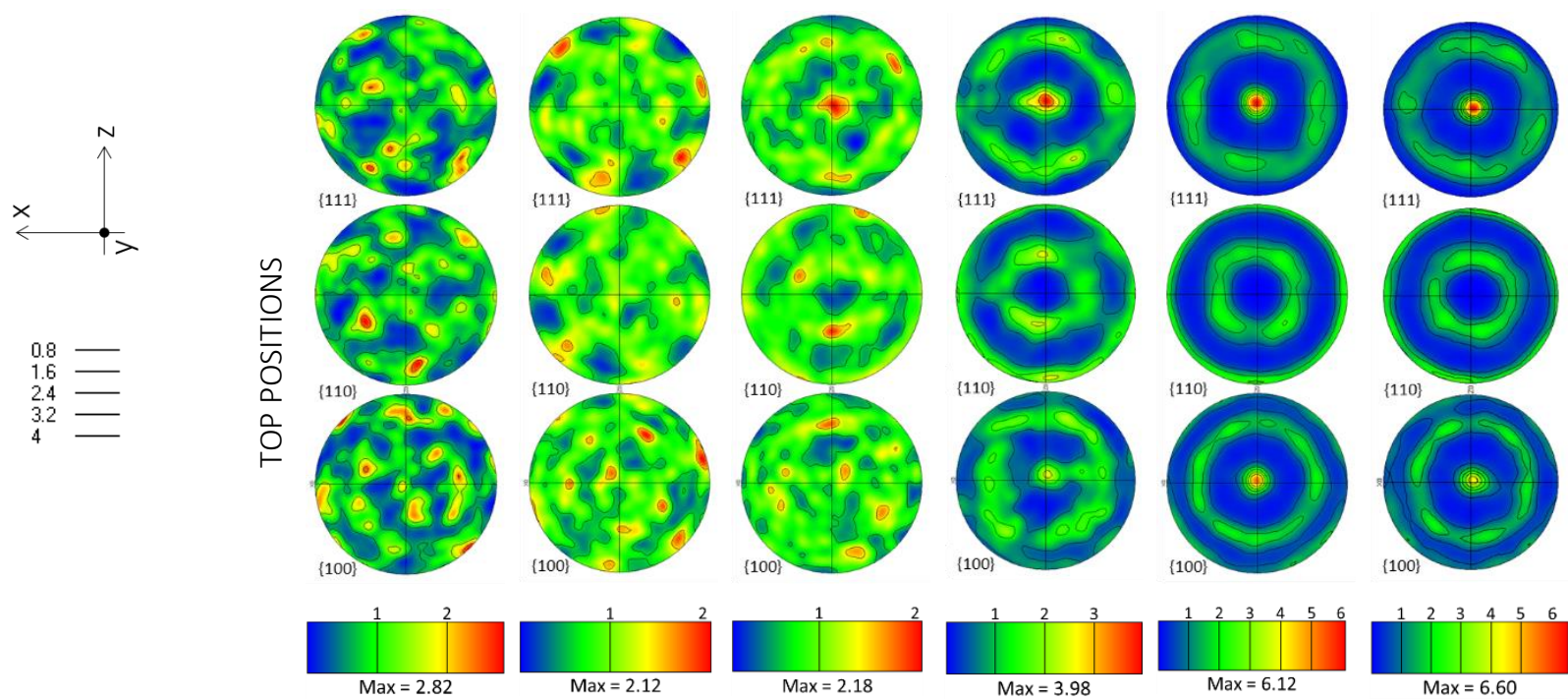

b) $25 \%$

c) $30 \%$

d) $50 \%$
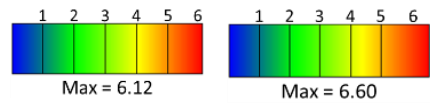

a) As-received
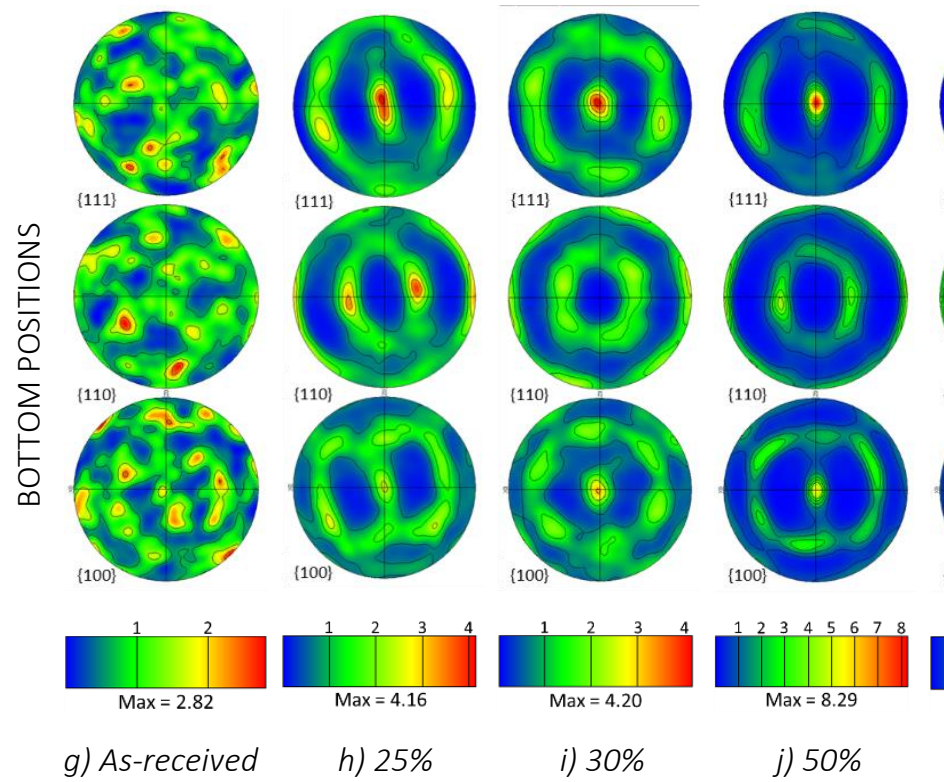

e) $65 \%$

f) $70 \%$
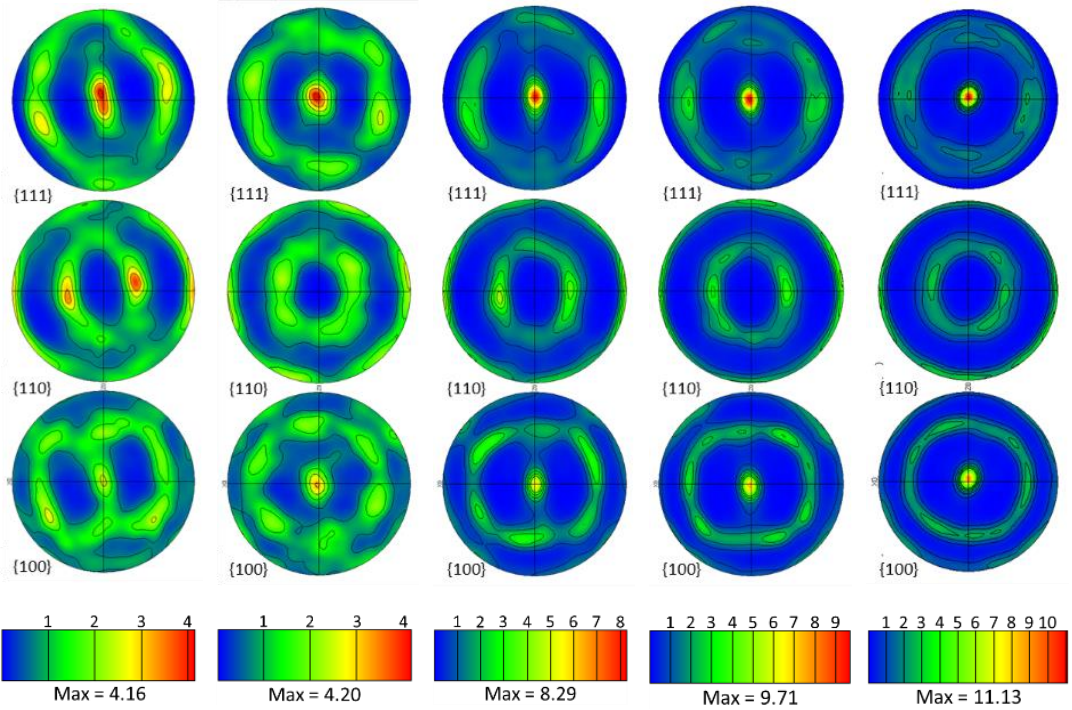

j) $50 \%$

k) $65 \%$

1) $70 \%$

Figure 9. $\{100\},\{110\}$ and $\{111\}$ pole figures of rotary forged flanged-test pieces at top $(a, b, c, d, e)$ and bottom positions $(g, h, l, j, k, l)$ with increasing thickness reduction (\%)

Analyzing the texture developed in flanged test-pieces (Figure 9), and considering the test pieces symmetry with respect to the imposed macroscopic deformation, the crystallographic texture exhibits a sharpening of centrosymmetric fibers about the surface normal direction (Y-axis) of the workpiece with increasing amount of deformation. With the exception of Figure 9.b and c which correspond to 25 and $30 \%$ of reduction, respectively, at top positions (dead zone), the intensity peaks are perfectly aligned to the centers of both $\{100\}$ and $\{111\}$ poles. 
As will be described in more detail in the discussion section, this texture clearly resembles the texture reported for uniaxial compression in bcc metals, described by a duplex $<111>+<100>$ fibers, with $<111>\|$ ND being the major component (Hu, 1974).

A close relationship between the level of deformation (Figure 8) and the corresponding texture intensity (Figure 9) is observed. The increase of both the apparent deformation and the alignment of the lath structure is translated into texture sharpening, not observing an apparent shift in either texture components or fibers. Therefore, it can be inferred that the same (main) mode of deformation is operating along the whole rotary forging process and across the flange thickness of the flanged-test pieces.

In order to study more in detail the texture evolution of rotary forged flanged-test pieces, Orientation Distribution Figures (ODF) were analyzed. Although the texture evolution in bcc metals has received significantly less attention than for fcc metals, the rolling and recrystallization texture of bcc steels are extensively studied. The texture of rolled bcc steels are mostly composed of certain orientation fibers which appear as straight lines in the Euler angle space (Holscher et al., 1991). Table 4 shows a list of texture fibers and components identified in bcc metals (Holscher et al., 1991, 1994), (Raabe et al., 1993), (Hutchinson, 1999), along with Figure 10 which shows the position of such texture fibers and components in (reduced) Euler space. The mostly partial, $\alpha$-fibre comprises the orientations with a common $\langle 110\rangle$ crystal axis parallel to the $R D$. that is, the orientations $\{h k l\}\langle 110\rangle$, which include the texture components $H, I$ and $E_{1}$ (see Figure 10.c, $\varphi_{2}=45^{\circ} \mathrm{ODF}$ section). The $\gamma$-fibre comprises the orientations with $\{111\}$ parallel to the $N D, \alpha$-fibre that is, the orientations $\{111\}\langle u v w\rangle$, including the $E$ and $F$ texture components. Other relevant texture components which evolve during thermomechanical processing of

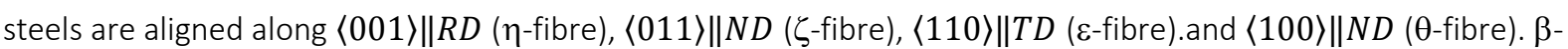
fibre is a skeleton line and comprises the true maxima of all sections along $\varphi_{1}$ and thus having variable $\varphi_{1}$ and $\Phi$ coordinates. This fibre is reported to be present in bcc textures, but it is a prominent in fcc rolling texture. 
Table 4. List of texture fibers and components of BCC materials (Hutchinson, 1999), (Holscher et al., 1991, 1994) and (Raabe et al., 1993).

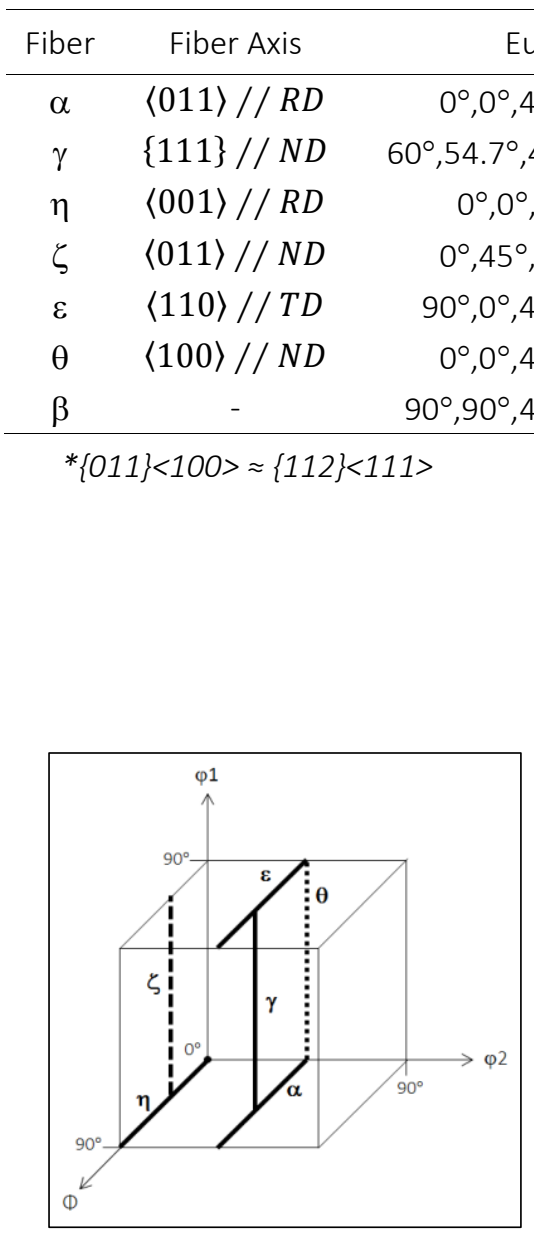

a)

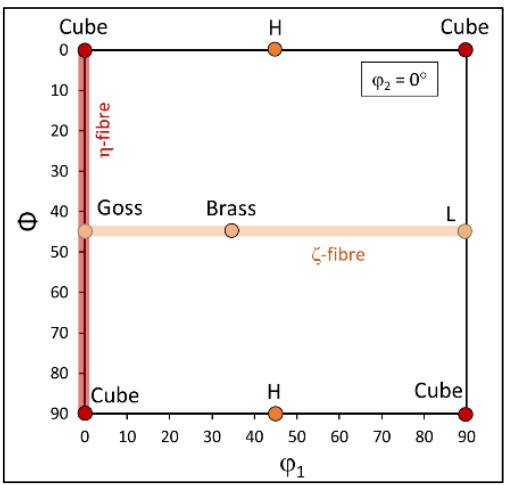

b)

\begin{tabular}{clcc}
\hline Component & $\{h k l\}\langle u v w\rangle$ & Code & Euler Angles \\
\hline $\begin{array}{c}\text { Cube } \\
\text { Rotated } \\
\text { cube }\end{array}$ & $\{001\}\langle 100\rangle$ & $\mathrm{C}$ & $45^{\circ}, 0^{\circ}, 45^{\circ}$ \\
- & $\{111\}\langle 110\rangle$ & $\mathrm{E}_{1}$ & $0^{\circ}, 55^{\circ}, 45^{\circ}$ \\
- & $\{111\}\langle 110\rangle$ & $\mathrm{E}_{2}$ & $60^{\circ}, 55^{\circ}, 45^{\circ}$ \\
- & $\{111\}\langle 11 \overline{2}\rangle$ & $\mathrm{F}_{1}$ & $30^{\circ}, 55^{\circ}, 45^{\circ}$ \\
- & $\{111\}\langle 11 \overline{2}\rangle$ & $\mathrm{F}_{2}$ & $90^{\circ}, 55^{\circ}, 45^{\circ}$ \\
- & $\{112\}\langle\overline{1} 10\rangle$ & $\mathrm{I}$ & $0^{\circ}, 35^{\circ}, 45^{\circ}$ \\
Goss & $\{110\}\langle 001\rangle$ & $\mathrm{G}$ & $90^{\circ}, 90^{\circ}, 45^{\circ}$ \\
Brass* & $\{110\}\langle 112\rangle$ & $\mathrm{B}$ & $57^{\circ}, 90^{\circ}, 45^{\circ}$ \\
\hline
\end{tabular}

*This orientation is known as the "Brass" in fcc rolling texture

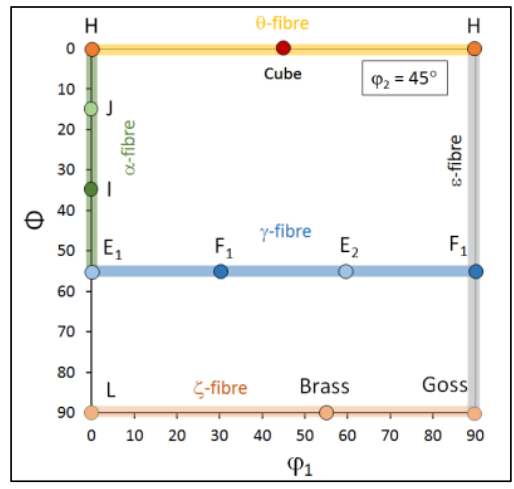

c)

Figure 10. a) Main orientation and fibres reported for bcc metals, b) $\varphi_{2}=0^{\circ} \mathrm{ODF}$ and; c) $\varphi_{2}=45^{\circ} \mathrm{ODF}$ sections.

Figure 11 and Figure 12 plots the texture evolution of the flanged test-pieces in the form of orientation distribution functions (ODF) figures and constant $\varphi_{2}=0^{\circ}$ and $45^{\circ}$ sections for top and bottom positions, respectively, with Euler angles plotted in the range $0^{\circ} \leq \varphi_{1}, \Phi \leq 90^{\circ}$ due to orthorhombic crystal symmetry. These sections were chosen since they contain the main texture fibers for bcc metals. From these latter figures, in direct comparison with the main orientation and fibres reported in bcc metals (Figure 10) it is obvious the sharpening of certain texture components located in the fibers $\langle 011\rangle \| R D$ ( $\alpha$-fibre), $\langle 011\rangle \| N D(\zeta$-fibre), and $\langle 100\rangle \| N D(\theta$ fibre). However, no texture component located in the $\langle 111\rangle \| N D$ ( $\gamma$-fiber) was found regardless the amount of deformation and/or position. 


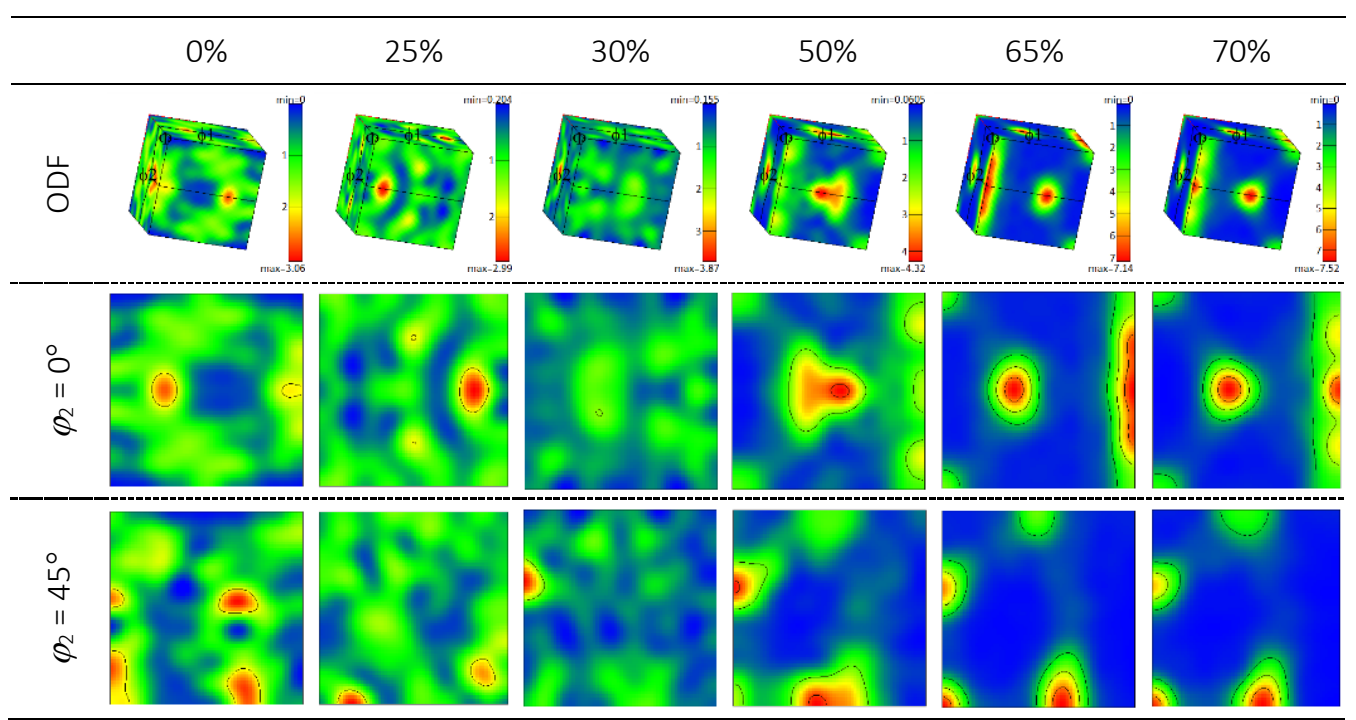

Figure 11. Evolution of ODF and $\varphi_{2}=0^{\circ}$ and $45^{\circ}$ const. sections $\left(\varphi_{2}\right.$ const. sections, $0^{\circ} \leq \varphi 1 \leq 90^{\circ}$ and $0^{\circ} \leq \phi \leq 90 \%$ with increasing thickness reduction (\%) of rotary forged flanges test-pieces at top positions.

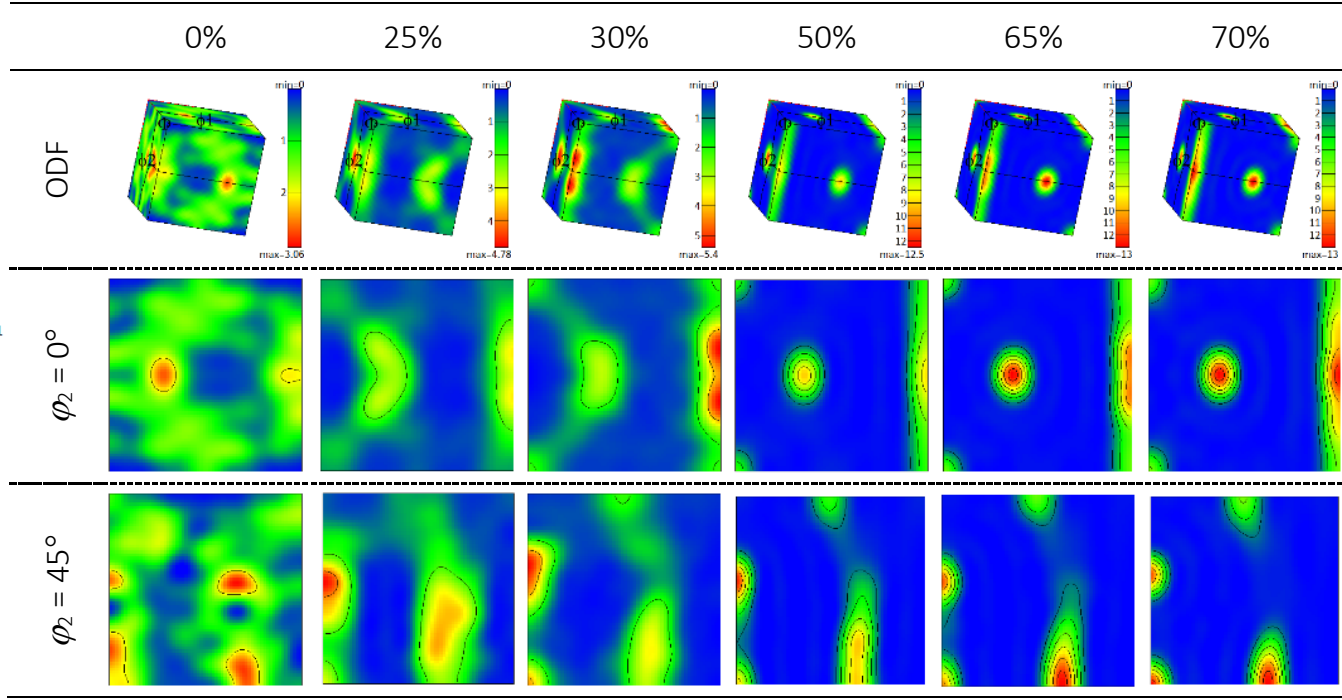

Figure 12. Evolution of ODF and $\varphi_{2}=0^{\circ}$ and $45^{\circ}$ const. sections $\left(\varphi_{2}\right.$ const. sections, $0^{\circ} \leq \varphi 1 \leq 90^{\circ}$ and $0^{\circ} \leq \phi \leq 90 \%$ with increasing thickness reduction (\%) of rotary forged flanges test-pieces at bottom positions.

In order to identify the specific texture components developed, the orientation density, $\mathrm{f}(\mathrm{g})$, along the $\alpha, \zeta$ and $\theta$-fibers are plotted in Figure 13 at bottom positions (maximum deformation). Due to cubic crystal symmetry, the $\zeta$-fibre (Figure 13.a) and $\alpha$-fibre (Figure 13.b) is shown in the range $0^{\circ} \leq \varphi_{1} \leq 90^{\circ}$ and $0^{\circ} \leq \phi \leq 90^{\circ}$, respectively, and the range $0^{\circ} \leq \varphi_{1} \leq 60^{\circ}$ is sufficient for the representation of the full $\theta$-fibre (Figure 13.c). From Figure 13 four texture components, $\{110\}\langle 112\rangle$ Brass, $\{110\}\langle 110\rangle L,\{112\}\langle 110\rangle$ I and $\{001\}\langle 100\rangle$ Cube, are found. 


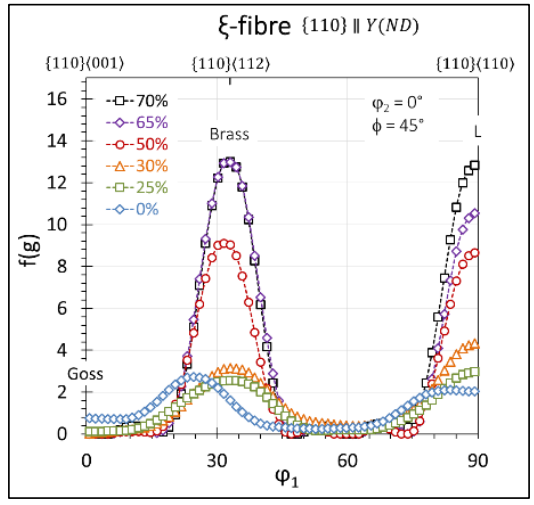

a)

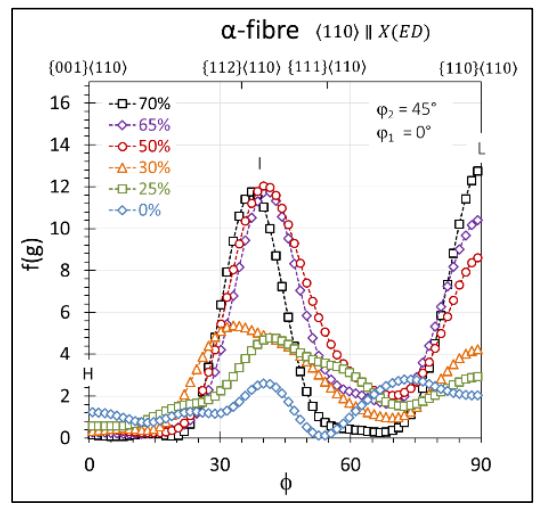

b)

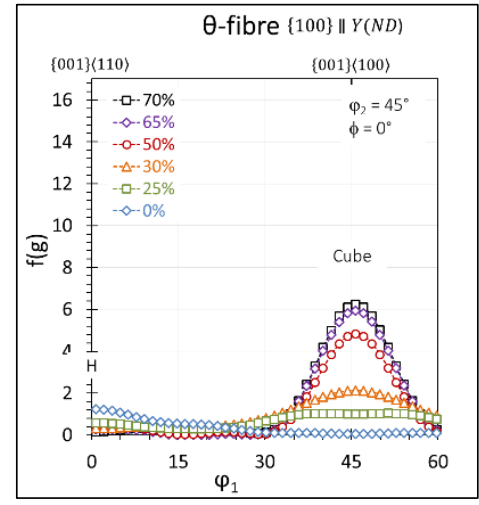

c)

Figure 13. Evolution of orientation density along $\zeta$,-fibre a), $\alpha$-fibre b) and $\theta$-fibre c) with increasing thickness reduction (\%) at bottom positions

The intensity evolution, $f(g)$, of the four texture components with increasing thickness reduction is plotted for both top (Figure 14.a) and bottom (Figure 14.b) positions. From Figure 14.b, the main findings are outlined below:

- Brass component $\{110\}\langle 112\rangle$ : As the reduction in thickness increases the intensity of the brass orientation increases gradually up to $65 \%$. No differences in texture intensity for 65 and $70 \%$ reduction was found.

- L component $\{110\}\langle 110\rangle$ : The intensity of this component increases linearly with deformation, not presenting a saturation level.

- I component $\{112\}\langle 110\rangle$ : The intensity increases sharply with a $50 \%$ of reduction, followed by saturation during subsequent deformation. However, the bell width of the orientation distribution, Figure 13.b, is reduced with increasing deformation, along with a shift of the intensity peak towards the ideal orientation.

- Cube component $\{001\}\langle 100\rangle$ : This is the weakest components found in the rotary forged test pieces. But similarly to $L$ component, the intensity of this component increases linearly with deformation, not presenting a saturation level.

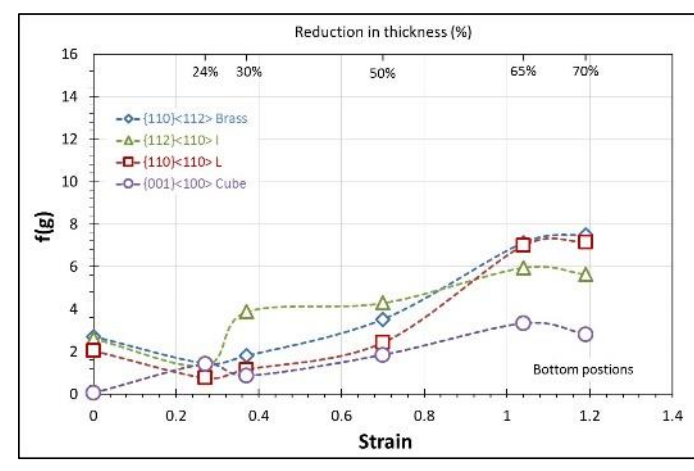

a) Top positions

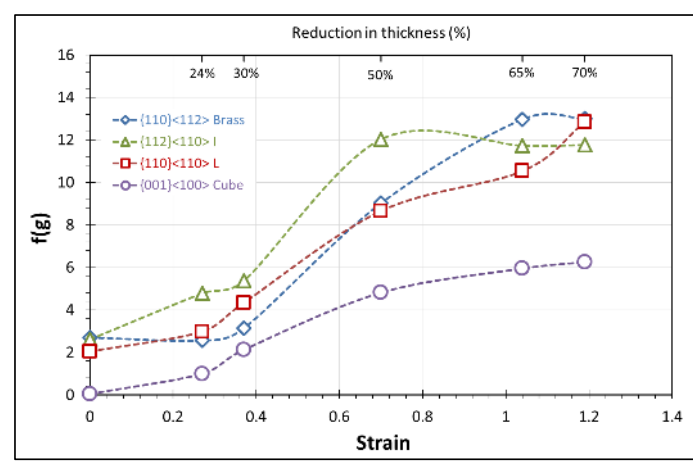

b) Bottom positions

Figure 14. Sharpening of texture components, $\{110\}\langle 112\rangle$ Brass, $\{110\}\langle 110\rangle L,\{112\}\langle 110\rangle /$ and $\{001\}\langle 100\rangle$ Cube, with increasing deformation at top (a) and bottom positions (b). 


\section{DISCUSSION}

\subsection{Metal flow and strain distribution}

Despite the large differences between conventional forging (upsetting) and rotary forging processes, characteristic features such as " $X$ " strain distribution together with the development of dead zones were also observed, denoting inhomogeneous strain distribution across the rotary forged flanged test-pieces (Figure 5). The formation of the characteristic " $X$ " in conventional upsetting is due to friction forces, resulting in shear bands and strain localization (Dieter et al., 2004). Such feature is also detected in the rotary forged test pieces (Figure 5). Deformation conditions such as tool design (contact pattern) (Hua et al., 2009b) and preform geometry (geometric effect) (Hua et al., 2009c) are an important factors on both grain flow evolution and hardness distribution in cold rotary forging, affecting the distribution of plastic deformation in a large degree. Aspects such as differences in the contact areas of the workpiece between top and bottom dies can be also playing an important role on the localization of plastic deformation (Hua et al., 2009a).

The "mushroom" effect in deformed cylindrical workpieces is the main deformation characteristic of rotary forging (Hua et al. 2009b), developing an inhomogeneous strain distribution across the flange thickness. However, in the present work, the rotary forged flanged-test pieces developed an inverted "mushroom shape" (asymmetrical bulging) at early stages of the process. Initially, the area contact at the bottom die is smaller than that at the upper die (see Figure 2), thus higher axial pressure on the metal near the bottom die is expected. Therefore, it is easier to satisfy the conditions for plastic deformation at bottom positions. This latter one could explain not only why initially the deformation is localized close to the bottom tool ( $25 \%$ thickness reduction, Figure 5.a), but also the formation of inverted "mushroom shape" (axisymmetric bulging) (Liu et al., 2004).

With increasing deformation, the gradual displacement of the center of the " $\mathrm{X}$ " strain distribution to relative higher positions across the thickness (Figure 8) is accompanied with the transition from the asymmetrical bulging, observed at early stages of deformation (25\%, Figure 5.a), to the final formation of symmetrical bulging (70\%, Figure 5.e). The reduction in the difference between contact areas of top and bottom dies as the rotary forging process proceeds could explain these latter observations.

Based on the analysis of grain flow patterns and hardness maps, see Figure 5, the complexity of the grain flow developed and the strain distribution in flanged-test pieces during rotary forging can be explained by means of two main deformation features: The stretching and flattening of the main deformation band "/" as the center of 
the " $X$ " strain distribution is displaced laterally with increasing deformation. The second feature is related to the realignment/bending of microstructural bands observed in the interior-top corner, originally aligned with the RD in as-received condition, which rotate almost $90^{\circ}$ towards the ED direction.

\subsection{Microstructural evolution of cold worked martensite}

The microstructural evolution of rotary forged flanged-test pieces was analyzed by EBSD. It can be seen in Figure 8, by means of a combination of IPF and BC maps, the structural changes which occur during rotary forging. The most obvious one is the shape change and strong alignment of the lath structure of Jethete M152 tempered martensite in a direction parallel to the compression plane, especially at bottom positions. As it can be inferred from Figure 8, the change of the shape of lath structure results in a large increase in the total grain boundary area and a reduction of lath/block width with increasing deformation. The change in the transverse size of the elongated (sub)structural elements could be simply explained by the reduction in the cross section of original grains that followed the overall change of the samples geometry. However, it is required the formation of new grain boundary area during deformation in order to compensate the shape change; and this is done by the incorporation of some of the dislocations that are continuously created during the deformation process (Humphreys et al., 2004). With the highest deformation (70\% reduction), cold-worked microstructures consist entirely on long lamellar structures, fully aligned parallel to the compression plane.

It is quite challenging to analyze the substructural changes which take place in severe deformed structures by means of EBSD technique, especially in martensitic structures. In contrast with ferrite-pearlite or austenitic structures, it is reported that the refined substructure and high density of dislocations in lath martensite in astemper condition accelerates evolution of deformed structure during cold deformation as reported by several authors (Tsuji et al., 2002), (Ueji et al., 2002, 2004), (Songa et al., 2006). The austenitizing and quenching can be considered as a pre deformation step raising the total strain significantly above the strain introduced during the subsequent deformation step (Hansen et al., 2008). Lath martensite has a three-level hierarchy in its morphology: lath, block and packet. Most of the block boundaries and the packet boundaries are high-angle boundaries. It can be said, therefore, that martensite has a kind of fine grained structure due to the martensitic transformation. Such high density of high-angle boundaries and complicated shape of blocks and packets would produce strong constraint effect during plastic deformation. The constraint causes inhomogeneous deformation (grain subdivision) to result in ultrafine deformation microstructure with large local misorientations. This is the main 
reported reason why martensitic starting microstructure is effective to produce ultrafine grains together with the inherent high dislocation density. In cold-worked structures, the increase in strength properties is accompanied by loss of ductility and toughness. The strong texture developed in the course of this process means that the properties of the final components are strongly dependent on the orientation (anisotropic properties) (Pérez, M., 2017a).

Although the analysis of cold-worked substructure in rotary forged test pieces is out of the scope of the present work, the effect of cold forming processes on low-carbon lath martensite by transmission electron microscopy is well described in literature. Hansen et al. (2008) studied the structure and strength of an IF steel after large strain deformation. The authors found that a feature associated to cold-worked martensite is the appearance of an internal structure within the grains, resulting from the accumulation of dislocations during cold deformation. At large rolling reduction the structure is a typical lamellar structure, with nearly planar boundaries and short interconnecting boundaries forming a bamboo structure. Ueji et al. (2002) studied that the microstructural changes during the martensite process in case of the $50 \%$ cold rolling in $0.13 \%$ C plain carbon steel. The $50 \%$ cold rolling of martensite mainly developed the ultrafine lamellar structure, which is typical for the severely deformed materials. This results are in agreement with Nedjad et al. (2008) who studied the microstructural evolution the lath martensite of a Fe-10Ni-7Mn maraging steel during cold rolling. The authors found that the deformed structure showed lamellar dislocation boundaries and shear bands, typical of deformed structure by heavy cold rolling. Takaki et al. (1992) studied the effect of cold working on lath martensite in $0.2 \% \mathrm{C}$ steel and they found that cold working in the lath martensite steel causes an intrusion of slip bands into the matrix, resulting in the destruction of lath martensitic structure and the formation of dislocation cell structure around slip bands together with an increase in dislocation density. For $80 \%$ reduction, almost $100 \%$ of "damaged lath martensite" was found. In areas of damaged martensite, a dislocation cell structure replaced the lath structure. Tianfu et al. (2006) also studied the impact of severe cold-rolling on original microstructure of a low carbon steel and they found that the microstructure of lath martensite after $93.6 \%$ cold rolling showed a lath width of $20 \mathrm{~nm}$, much smaller than that from starting lath martensite (as-tempered) with the average lath of $300 \mathrm{~nm}$ wide. The latter authors observed that most martensite laths were thinned and damaged and presenting very large misorientation after cold rolling. The reported descriptions of cold-worked martensite under a similar level deformation as that of flanged testpieces are in good agreement with the microstructural observations by EBSD in the present work. 


\subsection{Texture evolution - fibers (pole figures)}

During deformation the orientation of single crystals and individual grains change relative to the direction of applied stresses. It is well know that these changes are not random and involve rotations which are directly related to the crystallography of the deformation. The deformation occurs on the most favorably oriented slip or twinning systems and it follows that the deformed metal acquires a preferred orientation or texture (Humphreys et al., 2004), which becomes stronger as deformation proceeds.

In uniaxial deformation, such as tension, compression, wire drawing, or extrusion, usually leads to simpler textures than rolling, for example, since only one deformation axis is prescribed (Kocks et al., 1998). In uniaxial tension or wire drawing, bcc materials form $\langle 110\rangle$ fiber textures, as fcc materials deformed in compression. Vice versa, in compression of bcc metals, the textures can be described by two fibers with $\langle 111\rangle$ and $\langle 100\rangle$ parallel to the deformation axis (double fiber texture) (Kocks et al., 1998), which resemble the typical fcc tension textures. The resemblance of fcc and bcc deformation textures is due to reversing slip plane and slip direction as reported by Hölscher et al. (1994) and Kocks et al. (1998).

The preferred orientation produced by compression-rolling is a fiber-type texture with the compression axis as the fiber axis. For bcc metals and alloys, such as Fe and Si-ferrite, the compression texture is a duplex $<111>+$ $<100\rangle$, with $<111>\| \mid N D$ being the major component $(\mathrm{Hu}, 1974)$. In compression, when deformation occurs by single slip, the active slip-plane normal rotates toward the compression axis, whereas in tension it is the active slip direction that tends to align with the axis of the applied stress. In the compression of a polycrystalline aggregate, where multiple slip occurs, the direction of lattice rotation is opposite to that in tension (Kocks et al., 1998).

Analyzing the texture developed in rotary forged parts, as shown in Figure 9 by $\{100\},\{110\}$ and $\{111)$ pole figures, and considering the flanged-test piece symmetry with respect to the imposed macroscopic deformation, the crystallographic texture exhibits an increasing centro-symmetric fibers about the workpiece surface normal direction (Y-axis). The texture becomes sharper as strain increases. From Figure 9 it is clear that the texture developed in the course of rotary forging produces that a sharp texture with both $<100>$ and $<111>$ directions strongly aligned with ND direction (compression axis, Y), with $<111>|| N D$ being the stronger fiber. Figure 15.a shows the texture of flanged-test piece developed after a $70 \%$ of reduction at the bottom position (max. deformation), and Figure 15.b plots the texture associated to fibers $<100>\|\mathrm{Y}(\mathrm{ND})+<111>\| \mathrm{Y}(\mathrm{ND})$, considering $10^{\circ}$ 
as maximum angle of deviation. From this latter figure, it is possible to see the contribution of each fiber to the overall texture. Based on the resemblance between both figures, it is clear that the texture of rotary forged flanged-test piece can be explained by means of the combination of the double fiber texture $<100>+<111\rangle$ parallel to the compression axis of the rotary forging process. That means that, despite the complexity of this process in comparison with conventional forging, the flanged test-pieces develop a texture similar to that reported for uniaxial compression (Hu, 1974). Or in other words, axial compression is the main deformation mode for the flanged-test pieces.
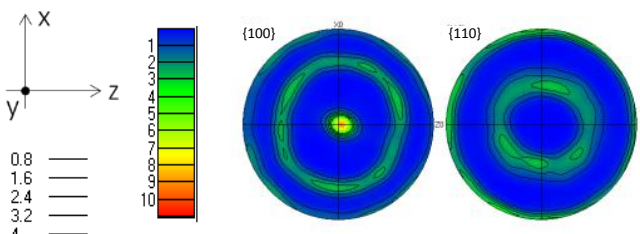

a)
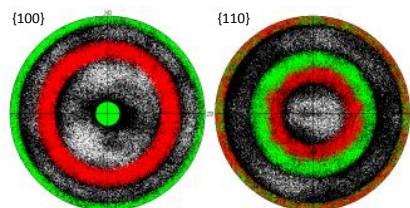

b)
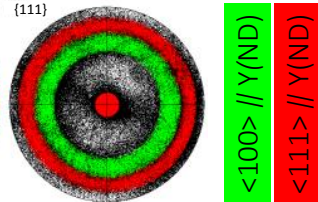

Figure 15. Texture developed of the rotary forged flanged-test piece at bottom position with a $70 \%$ of reduction a) $\{100\},\{110\}$ and $\{111\}$ pole figures, and b) $<100>/ / N D$ and $<111>/ / N D$ fibers denoted by green and red colors, respectively

In addition, Figure 16 and Figure 17 plot the increase of volume fraction of $<100>|| N D$ and $<111>|| N D$ fibers with increasing deformation of rotary forged flanged test-pieces. From Figure 17, there is lineal increase of the volume fraction of cold-worked martensite which has acquired the double fibre texture. With a $70 \%$ of reduction, above $70 \%$ of the texture of rotary forged test piece at the bottom position can be described by the double fiber texture. These results (Figure 17) also confirm that $<111>/ / N D$ is the predominant fiber in agreement with uniaxial compression in bcc metals, regardless the position (top, bottom) and/or level of deformation.

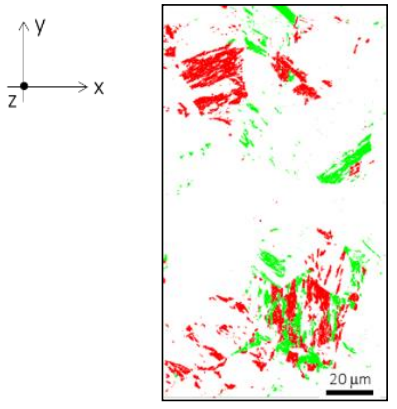

a) As-received

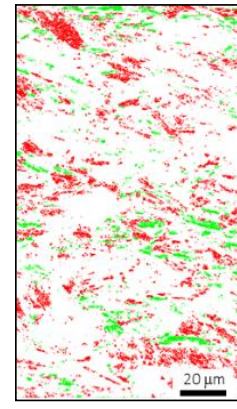

b) $25 \%$

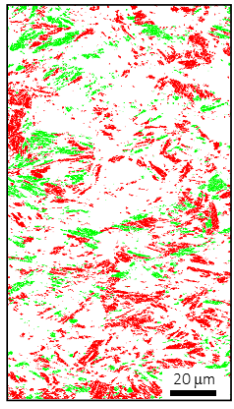

c) $30 \%$

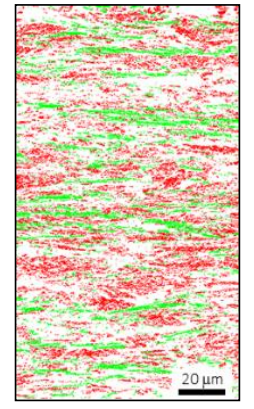

d) $50 \%$

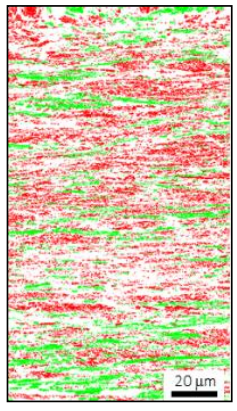

e) $65 \%$

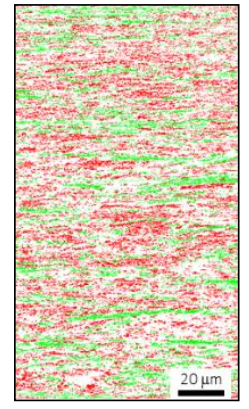

f) $70 \%$

Figure 16. Evolution of $\langle\mathbf{1 0 0}\rangle / / \boldsymbol{Y}(\mathbf{N D})$ (green color) and $\langle\mathbf{1 0 0}\rangle / / \boldsymbol{Y}(\boldsymbol{N D})$ (red color) fibers in the rotary forged flanged test-pieces at bottom positions (max. deformation). 

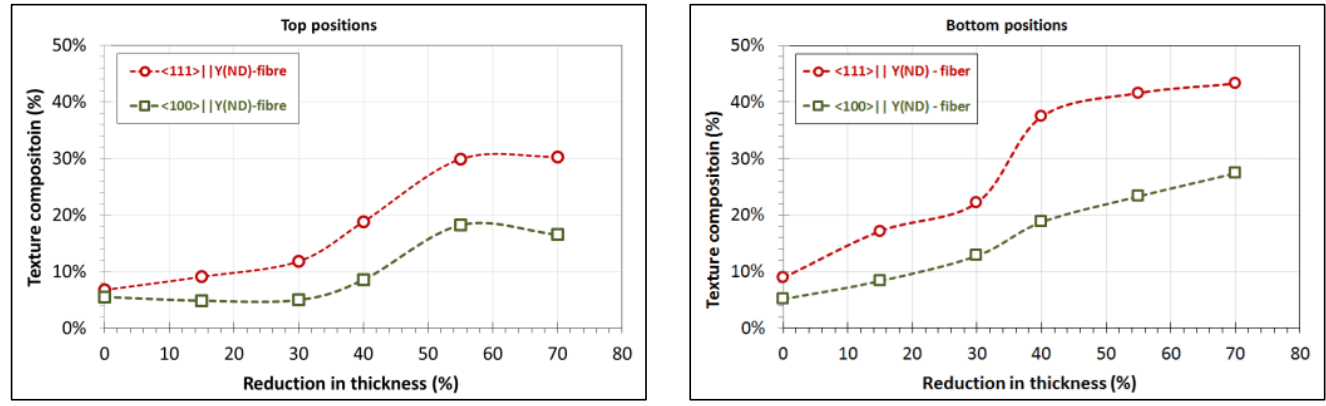

Figure 17. Volume fraction of material within $10^{\circ}$ of the given fibre texture of rotary forged flanged test-pieces

\subsection{Texture evolution - ODF}

The analysis of texture evolution by means Orientation Distribution Figures (ODF) reveals that 4 main texture components are developed in the course of rotary forging process: $L$ component $\{110\}\langle 110\rangle$, Brass component $\{110\}\langle 112\rangle, L$ component $\{110\}\langle 110\rangle$, Cube component $\{001\}\langle 100\rangle$ and / component $\{112\}\langle 110\rangle$. These results are partially in agreement with those published by Han et al. (2016). The authors studied the microstructure and texture evolution of cold rotary forged spur bevel gear of a ferritic-pearlite steel. The texture analysis of the region which undergo the most severe deformation matches with that found in the present work for $50 \%$ of thickness reduction at the bottom position. The $\varphi_{2}=45^{\circ}$ sections (ODF) are quite similar. Although the authors do not make any reference, a strong $\{110\}<112>$ texture (Brass component) is also observed in the $\varphi_{2}=45^{\circ}$ sections, in agreement as well with the present work. However, significant differences were found with respect to this work. The authors found that regions which undergoes slight deformation develop a strong $\gamma$-fiber ( $\{111\} \| N D)$. In regions with stronger deformation, $\alpha$-fiber is developed in detriment of $\gamma$-fiber. The authors concluded that $\alpha$ fibers continuously develop with increasing amount of deformation, being $\{112\}<110\rangle$ (/ component) the dominant component, and $\gamma$-fibers decrease when the deformation reaches a certain critical point.

In a similar fashion, for cold rolling in low-carbon steels the increasing of rolling deformation tends to shift the texture maxima from $\{001\}\langle 110\rangle(\mathrm{H})$ along $\alpha$-fibre over $\{112\}\langle 110\rangle(\mathrm{I})$ toward $\{111\}\langle 110\rangle(\mathrm{E})$ and $\mathrm{F} 111\}\langle 112\rangle(\mathrm{F})$ in the $\gamma$-fibre (Hölscher et al., 1991). For a ferritic stainless steel (Fe 16\% Cr), the cold rolled texture is similar to that of low carbon steel (Hölscher et al., 1991), with the only difference of a stronger rotated cube texture. In cold rolling for bcc metals, it is reported that $\alpha$ grains are more stable against rotation during rolling than the $\gamma$ grains (Kang et al., 2008). The stability is related to the accumulation of the stored energy during rolling, being the tendency of reorientation (instability) around the main components of the deformation texture proportional to the intragranular misorientation (Kang et al., 2007). However, in the present work no texture components 
associated to the $\gamma$-fiber are detected regardless the amount of deformation or position (top or bottom). No critical deformation was found in which a shift in either texture components or fibers are developed in detriment of other ones.

Future work is required in order to understand both the effect of the chemistry and microstructural parameters on the texture development and the role of the tool and preform geometry on strain distribution in cold rotary forging 


\section{CONCLUSIONS}

- A complex grain flow and inhomogeneous deformation patterns are developed in the course of the cold rotary forging process. A transition between asymmetrical bulging (inverted mushroom) to the final formation of a symmetrical bulging at the end of the process was observed, associated to initial differences in contact areas between upper and lower dies.

- $\quad$ The complexity of the grain flow developed in rotary forged flanged-test pieces can be explained by the formation of a main deformation band " $/$ " which run parallel to the bottom die, and the realignment/bending of microstructural bands observed in the interior-top corner, which rotate almost $90^{\circ}$ towards the ED direction.

- $\quad$ Remarkable structural changes were observed in the lath structure of Jethete M152 alloy during rotary forging. With the highest deformation (70\% flange reduction), the cold worked microstructure consists entirely on long lamellar structures, full aligned parallel to the compression plane of the rotary forging process (Y-axis, ND direction).

- The microstructural changes are accompanied by a strong sharpening of the crystallographic texture of cold rotary forged test specimens. The crystallographic texture clearly exhibits an increasing centrosymmetric fibers with $<100>$ and $<111>$ directions aligned with compression direction, with $<111>/ /$ ND being the stronger fiber. This double fiber texture is in good agreement with that reported for uniaxial compression in bcc metals.

- Despite the inherent complexity of the rotary forging process due to the continuous shifting of the contact area of the tool with the workpiece, uniaxial compression was found to be the main deformation mode of rotary forged flanged-text pieces.

- $\quad$ The ODF analysis reveals that 4 main texture components are developed in the course of rotary forging process: L component $\{110\}\langle 110\rangle$, Brass component $\{110\}\langle 112\rangle, L$ component $\{110\}\langle 110\rangle$, Cube component $\{001\}\langle 100\rangle$ and I component $\{112\}\langle 110\rangle$. In contrast with reported literature for bcc metals, no texture component associated to $\gamma$-fiber $(\{111\} \| N D)$ was found, regardless the amount of deformation or location. 


\section{ACKNOWLEDGEMENTS}

The work presented in this paper was funded by Innovate UK under SAMULET 2 Project 10.5 / Contract Ref TSB 113006. The author would like to acknowledge especially both Peter Standring (University of Nottingham) for conducting the rotary forging trials and Professor Bradley P. Wynne (University of Sheffield) for his useful comments and fruitful discussion. The author is also grateful to Rolls-Royce and the Advanced Forming Research Centre (AFRC), and in particular Lisa Muir and Alastair Conway, for the support and help provided. 


\section{REFERENCES}

Baczynski, J., Jonas, J.J., 1996. Texture development during the torsion testing of a-iron and two IF steels. Acta Mater. 44(11), 4273-4288. (http://dx.doi.org/10.1016/1359-6454(96)00114-0).

Beyerlein, I.J., Tóth, L.S., 2009. Texture evolution in equal-channel angular extrusion. Prog. Mater. Sci. 54(4), 427-510. (http://dx.doi.org/10.1016/j.pmatsci.2009.01.001).

Bhowmik, A., Biswas, S., Suwas, S., Ray, R.K., Bhattacharjee, D., 2009. Evolution of grain-boundary microstructure and texture in interstitial-free steel processed by equal-channel angular extrusion. Metall. Mater. Tran. A 40, 2729-2742. (doi: 10.1007/s11661-009-9939-5).

Deng, X., Hua, L., Han, X., Song, Y., 2011. Numerical and experimental investigation of cold rotary forging of a 20CrMnTi alloy spur bevel gear. Mater. Des. 32(3), 1376-1389.

(http://dx.doi.org/10.1016/j.matdes.2010.09.015).

Dieter, G.E., Kuhn, H.A., Semiatin, S.L., 2004. Handbook of Workability and Process Design. (2nd ed.) ASM International, USA, pp 57-60.

Engler, O., Randle, V., 2009. Introduction to Texture Analysis: Macrotexture, microtexture and orientation mapping, second ed. CRC press, pp. 3-14.

Han, X., Dong, L., Hua, L., Zhuang, W., 2016. Microstructure and texture evolution in cold rotary forging of spur bevel gears on 20CrNiMnTi alloy steel. J. Mater. Eng. Perform. 25(3), 1182-1190. (doi: 10.1007/s11665-016-1929-3).

Hansen, N., Huang, X., Kamikawa, N., 2008., Structure and strength of IF steel after large strain deformation. In: A. Haldar, S. Suwas, D. Bhattacharjee (eds), Microstructure and Texture in Steels. Springer, London, 2008, pp. 33-42. (doi: 10.1007/978-1-84882-454-6_3).

Herrera, C., Lima, N.B., Ferreira, A., Plaut, R.L., Padilha, A.F., 2009. Texture and mechanical properties evolution of a deep drawing medium carbon steel during cold rolling and subsequent recrystallization. J. Mater. Process. Technol. 209(7), 3518-3524. (http://dx.doi.org/10.1016/j.jmatprotec.2008.08.007).

Hölscher, M., Raabe, D., Lucke, K., 1991. Rolling and recrystallization textures of bcc steels. Steel Res. Int. 62(12), 567-575. (doi: 10.1155/TSM.14-18.585).

Hölscher, M., Raabe, D., Lücke, K., 1994. Relationship between rolling textures and shear textures in f.c.c. and b.c.c metals. Acta Metall. Mater. 42(3), 879-886. (http://dx.doi.org/10.1016/0956-7151(94)90283-6).

Hu, H., 1974. Texture of metals. Texture 1, 233-258. (http://dx.doi.org/10.1155/TSM.1.233).

Hua, X, Hua, L., 2009a. Comparison between cold rotary forging and conventional forging. J. Mech. Sci. Technol. 23, 2668-2678. (doi: 10.1007/s12206-009-0624-9). 
Hua, X., Hua, L., 2009b. Effect of size of the cylindrical workpiece on the cold rotary-forging process. Mater.

Des. 30, 2802-2812. (http://dx.doi.org/10.1016/j.matdes.2009.01.021).

Hua, X., Hua, L., 2009c. Plastic deformation behaviours of cold rotary forging under different contact patterns by 3D Elastic-Plastic FE Method. Mater. Tran. JIM, 50 (8), 1949-1958.

(http://doi.org/10.2320/matertrans.M2009140).

Humphreys, F.J., Hatherly, M., 2004. Recrystallization and related annealing phenomena. second ed. Oxford: Elsevier, Oxford, pp 215-266.

Hutchinson, B., 1999, Deformation microstructures and textures in steels. Phil. Trans. R. Soc. Lond. A 357, 1471-1485. (https://doi.org/10.1098/rsta.1999.0385)

Inagaki, H., 1994. Fundamental aspect of texture formation in low carbon steel. ISIJ Int. 34, 313-321. (http://doi.org/10.2355/isijinternational.34.313).

Inagaki, H., Suda, T., 1972. The development of rolling textures in low-carbon steels. Texture 1(2), 129-140. (http://dx.doi.org/10.1155/TSM.1.129).

Kang, J.-Y., Bacroix, B., Réglé, H., Oh, K.H., Lee, H.-C., 2007. Effect of deformation mode and grain orientation on misorientation development in body-centered cubic steel. Acta Mater. 55(15), 4935-4946. (http://dx.doi.org/10.1016/j.actamat.2007.05.014).

Kang, J.Y., Kim, D.I., Lee, H.C., 2008. Texture Development in low carbon sheet steels for automotive applications. In: A. Haldar, S. Suwas, D. Bhattacharjee (eds), Microstructure and Texture in Steels. Springer, London, 2008, pp. 85-101. (doi: 10.1007/978-1-84882-454-6_5).

Kocks, U.F., Tomé, C.N., Wenk, H.-R., 1998. Texture and Anisotropy: Preferred orientation in polycristals and their effect on materials properties. First ed. Cambrigde University Press, Cambrigde, pp. 191-202.

Krauss, G., 1999. Martensite in steel: strength and structure. Mater. Sci. Eng. A 273-275, 40-57. (http://dx.doi.org/10.1016/S0921-5093(99)00288-9).

Li, S., Beyerlein, I.J., 2005a. Modelling texture evolution in equal angular extrusion of bcc materials: effect of processing route and initial texture. Modelling Simul. Mater. Sci. Eng. 13, 509-530. (doi:10.1088/09650393/13/4/003).

Li, S., Beyerlein, I.J., Bourke, M.A.M., 2005b. Texture formation during equal channel angular extrusion of fcc and bcc materials: comparison with simple shear. Mater. Sci. Eng. A 394(1-2), 66-77.

(http://dx.doi.org/10.1016/j.msea.2004.11.032). 
Li, S., Gazder, A.A., Beyerlein, I.J., Pereloma, E.V., Davies, C.H.J., 2006. Effect of processing route on microstructure and texture development in equal channel angular extrusion of interstitial-free steel. Acta Mater. 54(4), 1087-1100. (http://dx.doi.org/10.1016/j.actamat.2005.10.042).

Liu, G., Yuan, S., Zhang, M., Chi, L., 2001. Numerical analysis on rotary forging mechanism of a flange. J. Mater. Sci. Technol. 17(1), 129-130.

Liu, G., Yuan, S.J., Wang, Z.R., Zhou, D.C., 2004. Explanation of the mushroom effect in the rotary forging of a cylinder. J. Mater. Process. Technol. 151(1-3), 178-182. (http://dx.doi.org/10.1016/j.jmatprotec.2004.04.035).

Mangas, A., Santos, M., San Jose, J., Atxaga, G., Adarraga, O., 2012. Microstructural behaviour in Rotary Forging of Inconel 718. Key Eng. Mater. 504-506, 169-174. (doi:10.4028/www.scientific.net/KEM.504506.169).

Mangas, A., Santos, M., Zarazua, J.I., San Jose, J., Atxaga, G., Adarraga, O., 2013. Sensitivity analysis to optimise the microstructural properties of an Inconel 718 component manufacturing by rotary forging. Key Eng. Mater. 554-557, 234-247. (doi:10.4028/www.scientific.net/KEM.554-557.234).

Nedjad, S.H., Ahmadabadi, M.N., Furuhara, T., 2008. The extent and mechanism of nanostructure formation during cold rolling and aging of lath martensite in alloy steel. Mater. Sci. Eng. A 485(1-2), 544-549. (http://dx.doi.org/10.1016/j.msea.2007.08.008).

Nowak, J., Madej, L., Ziolkiewicz, S., Plewinski, A., Grosman, F., Pietrzyk, M., 2008. Recent development in orbital forging technology. Int. J. Metal Form. 1, 387-390. (doi: 10.1007/s12289-008-0076-2).

Parida, P.K., Dasgupta, A., Saibaba, S., 2013. Study of microstructure and microtexture of modified $9 \mathrm{Cr}-1 \mathrm{Mo}$ steel subjected to high deformation. J. Nucl. Mater. 432(1-3), 450-454. (http://dx.doi.org/10.1016/j.jnucmat.2012.08.031).

Pérez, M., 2017a. Analysis of innovate incremental cold forming process for the manufacturing of aerospace rotating parts (MSEC2017-2774). Proceedings of the ASME 2017 12th International Manufacturing Science and Engineering Conference (MSEC 2017), Los Angeles, USA.

Pérez, M., 2017b. Impact of annealing treatments on the softening and work hardening behaviour of Jethete M152 alloy for subsequent cold forming processes. Mater. Sci. and Eng. A 690, 303-313. (http://dx.doi.org/10.1016/j.msea.2017.03.012).

Plancak, M.E., Vilotic, D.Z., Stefanovic, M.C., Movrin, D.Z., Kacmarcik, I.Z., 2012. Orbital forging - a plausible alternative for bulk metal forming. J. Trends Dev. Mach. Assoc. Technol. 16(1), 35-38.

Raabe, D., Lucke, K., 1993. Textures of ferritic stainless steels. Mater. Sci. Technol. 9(4), 302-312. (doi: 10.1179/026708393790172132). 
Raabe, D., Lücke, K., 1994. Rolling and annealing textures of bcc metal. Mater. Sci. Forum 157-162, 597-610. (doi: 10.4028/www.scientific.net/MSF.157-162.597).

Sidor J.J., Verbeken, K., Gomes, E., Schneider, J., Rodrigez Calvillo, P., Kestens, L.A.I., 2012. Through process texture evolution and magnetic properties of high Si non-oriented electrical steels. Mater. Charact. 71, 4957. (http://dx.doi.org/10.1016/j.matchar.2012.06.006).

Songa, R., Ponge, D., Raabe, D., Speer, J.G., Matlock, D.K., 2006. Overview of processing, microstructure and mechanical properties of ultrafine grained bcc steels. Mater. Sci. Eng. A 441(1-2), 1-17. (http://dx.doi.org/10.1016/j.msea.2006.08.095).

Standring, P.M., 1999. The significance of nutation angle in rotary forging. In: Proceedings of 6th ICTP Congress, Nuremberg, Germany, pp. 1739-1744.

Standring, P.M., 2001. Characteristics of rotary forging as an advanced manufacturing tool. Proc. Inst. Mech. Eng, B 215(7), 935-945.

Standring, P.M., Moon, J.R., Appleton E., 1980. Plastic deformation produced during indentation phase of rotary forging. Metals Technology 7(1), 159-166. (http://dx.doi.org/10.1179/030716980803286784).

Takaki, S., lizuka, S., Tomimura, K., 1992. Y. Tokunaga, Influence of cold working on recovery and recrystallization of lath martensite in 0.2\%C steel. Mater. Tran. JIM 33(6), 577-584. (http://doi.org/10.2320/matertrans1989.33.577).

Tianfu, J., Yuwei, G., Guiying, Q., Qun, L., Wiansheng, W., Wei, W., Furen, X., Dayong, C., Xinju, S., Xin, Z., 2006. Nanocrystalline steel processed by severe rolling of lath martensite. Mater. Sci. Eng. A 432(1-2), 216220. (http://dx.doi.org/10.1016/j.msea.2006.06.047).

Tsuji, N., Ueji, R., Minamino, Y., Saito, Y., 2002. A new and simple process to obtain nano-structured bulk lowcarbon steel with superior mechanical property. Scrip. Mater. 46(4), 305-310. (http://dx.doi.org/10.1016/S1359-6462(01)01243-X).

Ueji, R., Tsuji, N., Minamino, Y., Koizumi, Y., 2002. Ultragrain refinement of plain low carbon steel by cold rolling and annealing of martensite. Acta Mater. 50(16), 4177-4189. (http://dx.doi.org/10.1016/S13596454(02)00260-4).

Ueji, R., Tsuji, N., Minamino, Y., Koizumi, Y., 2004. Effect of rolling reduction on ultrafine grained structure and mechanical properties of low-carbon steel thermomechanically processed from martensite starting structure. Sci. Technol. Advanc. Mater. 5(1-2), 153-162. (http://dx.doi.org/10.1016/j.stam.2003.10.017).

Yan, H., Bi, H., Li, H., Xu, Z., 2009. Microstructure, texture and grain boundaries character distribution evolution of ferritic stainless steel during rolling process. J. Mater. Process Technol. 209(5), 2009, 2627 2631. (http://dx.doi.org/10.1016/j.jmatprotec.2008.06.012). 


\section{FIGURE CAPTIONS}

Figure 1. Schematic representation of rotary forging of flanged test-pieces.

Figure 2. Comparison between the initial preform (left side) and a rotary forged test piece with a 70\% of reduction (right side).

Figure 3. Sequence of rotary forged flanged-test pieces with increasing thickness reduction Figure 4. GOM scans of top a) and bottom b) surface of the rotary forged flanged test piece with 70\% of thickness reduction.

Figure 5. Evolution of grain flow pattern and hardness distribution of flanged-test pieces in the course of rotary forging process.

Figure 6. Lateral and vertical displacement of the center of " $X$ " shape (open circles) and evolution of the main deformation band"I" (dotted lines) in rotary forged parts with increasing thickness reductions (\%)

Figure 7. Evolution of the relative position of the center of " $X$ " shape with respect the bottom die $(d / t)$.

Figure 8. Microstructural evolution of rotary forged test-pieces in as-tempered condition (a \& $\mathrm{g}$ ) with increasing amount of thickness reduction (\%) at top $(b, c, d, e, f)$ and bottom positions $(h, l, j, k, l)$, by means of a combination inverse pole figures (IPF) + band contrast maps (BC).

Figure 9. $\{100\},\{110\}$ and $\{111\}$ pole figures of rotary forged flanged-test pieces at top $(a, b, c, d, e)$ and bottom positions $(g, h, l, j, k, l)$ with increasing thickness reduction (\%)

Figure 10. a) Main orientation and fibres reported for bcc metals, b) $\varphi_{2}=0^{\circ}$ ODF and; c) $\varphi_{2}=45^{\circ}$ ODF sections.

Figure 11. Evolution of ODF and $\varphi_{2}=0^{\circ}$ and $45^{\circ}$ const. sections ( $\varphi_{2}$ const. sections, $0^{\circ} \leq \varphi 1 \leq 90^{\circ}$ and $0^{\circ} \leq \phi \leq 90^{\circ}$ ) with increasing thickness reduction (\%) of rotary forged flanges test-pieces at top positions. 
Figure 12. Evolution of ODF and $\varphi_{2}=0^{\circ}$ and $45^{\circ}$ const. sections ( $\varphi_{2}$ const. sections, $0^{\circ} \leq \varphi 1 \leq 90^{\circ}$ and $0^{\circ} \leq \phi \leq 90^{\circ}$ ) with increasing thickness reduction (\%) of rotary forged flanges test-pieces at bottom positions.

Figure 13. Evolution of orientation density along $\zeta$,-fibre a), $\alpha$-fibre b) and $\theta$-fibre c) with increasing thickness reduction (\%) at bottom positions

Figure 14. Sharpening of texture components, $\{110\}\langle 112\rangle$ Brass, $\{110\}\langle 110\rangle L,\{112\}\langle 110\rangle /$ and $\{001\}\langle 100\rangle$ Cube, with increasing deformation at top (a) and bottom positions (b).

Figure 15. Texture developed of the rotary forged flanged-test piece at bottom position with a $70 \%$ of reduction a) $\{100\},\{110\}$ and $\{111\}$ pole figures, and $b)<100>/ / N D$ and $<111>/ / N D$ fibers denoted by green and red colors, respectively

Figure 16. Evolution of $\mathbf{1 0 0} / / \mathbf{Y}(\mathbf{N D})$ (green color) and $\mathbf{1 0 0} / / \boldsymbol{Y}(\boldsymbol{N D})$ (red color) fibers in the rotary forged flanged test-pieces at bottom positions (max. deformation).

Figure 17. Volume fraction of material within $10^{\circ}$ of the given fibre texture of rotary forged flanged test-pieces 


\section{TABLE CAPTIONS}

Table 1. Jethete M152 chemical composition

Table 2. Geometry evolution of rotary forged flanged-test pieces

Table 3. Geometrical tolerances of rotary forged flanged-test pieces

Table 4. List of texture fibers and components of BCC materials 